\title{
Tunable Dielectric Materials and Devices for Broadband Wireless Communications
}

\author{
Carl H. Mueller and Félix A. Miranda \\ NASA Glenn Research Center \\ Communications Technology Division \\ 21000 Brookpark Road
}

Cleveland, Ohio 44135

\begin{abstract}
Wireless and satellite communications are a rapidly growing industries which are slated for explosive growth into emerging countries as well as countries with advanced economies. The dominant trend in wireless communication systems is towards broadband applications such as multimedia file transfer, video transmission and Internet access. These applications require much higher data transmission rates than those currently used for voice transmission applications. To achieve these higher data rates, substantially larger bandwidths and higher carrier frequencies are required. A key roadblock to implementing these systems at K-band $(18-26.5 \mathrm{GHz})$ and $\mathrm{Ka}-\mathrm{band}(26.5-40 \mathrm{GHz})$ is the need to develop hardware which meets the requirements for high data rate transmission in a cost effective manner. In this chapter, we report on the status of tunable dielectric thin films for devices, such as resonators, filters, phased array antennas, and tunable oscillators, which utilize nonlinear tuning in the control elements. Paraelectric materials such as Barium Strontium Titanate $\left((\mathrm{Ba}, \mathrm{Sr}) \mathrm{TiO}_{3}\right)$ have dielectric constants which can be tuned by varying the magnitude of the electric field across the material. Therefore, these materials can be used to control the frequency and/or phase response of various devices such as electronically steerable phased array antennas, oscillators, and filters. Currently, tunable dielectric devices are being developed for applications which require high tunability, low loss, and good RF power-handling capabilities at microwave and millimeter-wave frequencies. These properties are strongly impacted by film microstructure and device design, and considerable developmental work is still required. However, in the last several years enormous progress has occurred in this field, validating the
\end{abstract}


potential of tunable dielectric technology for broadband wireless communication applications. In this chapter we summarize how film processing techniques, microwave test configurations, and prototype devices have combined to drive the field to its current stage of development. 
Tunable Dielectric Materials and Devices for Broadband Wireless Communications

Keywords-Ferroelectric, Paraelectric, Thin Film, Broadband Communications, Wireless, Ka-Band, Tunable Components, Phased Array Antenna, Filters, Intermodulation Distortion.

\section{Nomenclature}

\begin{tabular}{|c|c|}
\hline AFM & Atomic force microscopy \\
\hline ATM & Asynchronous transfer mode \\
\hline BER & Bit error rate \\
\hline BSTO & Barium strontium titanate $\left(\mathrm{Ba}_{x} \mathrm{Sr}_{1-x}\right) \mathrm{TiO}_{3}$ \\
\hline $\mathrm{dB}$ & Decibel \\
\hline GEO & Geosynchronous Earth orbit \\
\hline $\mathrm{GHz}$ & Gigahertz \\
\hline IMD & Intermodulation distortion \\
\hline Ka-band & $26.5-40 \mathrm{GHz}$ \\
\hline K-band & $18-26.5 \mathrm{GHz}$ \\
\hline Kbps & Kilobits per second \\
\hline $\mathrm{KHz}$ & Kilohertz \\
\hline Ku-band & $12-18 \mathrm{GHz}$ \\
\hline L-band & $1-2 \mathrm{GHz}$ \\
\hline LEO & Low earth orbit \\
\hline LMDS & Local multipoint distribution service \\
\hline Mbps & Megabits per second \\
\hline $\mathrm{MHz}$ & Megahertz \\
\hline PCS & Personal communication services \\
\hline PSZT & Lead strontium zirconium titanate \\
\hline Q & Quality factor \\
\hline QAM & Quadrature amplitude modulation \\
\hline STO & Strontium titanate $\left(\mathrm{SrTiO}_{3}\right)$ \\
\hline $\operatorname{Tan} \delta$ & Dissipation factor \\
\hline
\end{tabular}




$\begin{array}{ll}\text { YBCO } & \text { Yttrium barium copper oxide } \\ \varepsilon_{\mathrm{r}} & \text { Dielectric constant } \\ \lambda_{0} & \text { Wavelength (free space) }\end{array}$

\section{Introduction}

Frequency and phase tunable devices using tunable dielectric materials such as $\mathrm{Ba}_{x} \mathrm{Sr}_{1-\mathrm{x}} \mathrm{TiO}_{3}$ (BSTO) and $\mathrm{SrTiO}_{3}(\mathrm{STO})$ as tuning components are being developed for use in next-generation, broadband wireless communication systems. Wireless communication is in the midst of an explosive growth which is expected to continue for several years [1]. At present, wireless phone use is concentrated in highly developed countries, where over $15 \%$ of the population may own mobile phones. Conversely, the wireless penetration rate in underdeveloped countries is generally less than $1 \%[2,3]$. Next-generation service providers have established several goals designed to improve the capabilities of wireless communication systems and increase the attractiveness and affordability of this technology to a wider range of people. The first goal is to expand coverage to more areas via the use of satellite systems. Many people in underdeveloped countries have no access to phones of any type, and wireless systems are usually a more cost-effective means of providing service than wired networks [4,5]. A reliable, easily accessible telecommunications infrastructure is essential to a solid economy, and most emerging nations are interested in using wireless systems as a means of building this infrastructure. A schematic diagram illustrating the Iridium satellite communication system is shown in Figure 1. This diagram illustrates that although a satellite system is comprised of various links, the most prevalent link is the user-to-satellite link. In order to provide commercial service, it is essential that the subscriber terminal is affordable to individual users. Current technology is capable of providing low-cost links at L-band (1-2) GHz, but the current cost of K-band (18-26.5) and higher frequency terminals is too high for individual subscribers. The main objective of this work is to advance tunable dielectric technologies which contribute towards the development of low-cost user terminals which support large bandwidth applications at Ka-band frequencies $(26.5-40 \mathrm{GHz})$. Global satellite communication systems which utilize L-band user-to-satellite links are already in place. Iridium became operational in 1998, and provides world-wide voice and data 
transfer services. Other satellite systems which will provide similar services are Globalstar and ICO [6]. Second, an array of new services will become available to wireless users. In addition to voice telephony, future broadband wireless applications include video conferencing, real-time multimedia file transfer, remote access to corporate local area networks, high-speed Internet access, and interactive video [7,8]. These applications require substantially higher data transmission rates and larger bandwidths than current satellite or land-based wireless systems can offer. Third, an infrastructure which allows for seamless unification of the many diverse wireless systems must be developed [1,9]. Next-generation mobile phones and other wireless communication systems must be capable of adapting to and operating in systems with different standards, networks, and operating frequencies, thus making communications anytime, anywhere a reality. The frustration of having a mobile phone which only operates in specific geographic areas is widely shared, and the advantages and conveniences of mobile phones which operate across different systems to provide seamless coverage throughout the world are obvious. One needs only to examine cases such as the growth of the Internet and use of personal computers to find evidence that public acceptance of new technologies is strongly correlated to how easy they are to use; systems which require a high level of user expertise rarely achieve market success, whereas technologies which are simple to operate and perform useful functions often experience explosive growth.



Figure 1. - Pictoral overview of the Iridium System. Note that user-to-satellite link is at L-band. Reprinted by permission of John Wiley \& Sons, Inc. ${ }^{12}$. 
There is a close correlation between the mobile-to-satellite uplink frequency and the maximum data transmission rate of the system because the maximum data transmission rate is proportional to bandwidth, and large bandwidth channels are only available at high carrier frequencies. Other factors which limit data transmission rates are the low transmit RF power levels of mobile terminals, and the need to use inexpensive components which are often plagued by relatively low quality factor $(\mathrm{Q})$ values. These parameters are dictated by cost, weight, and size requirements. To achieve higher bandwidths and thus higher data transmission rates, higher uplink frequencies must be used. This trend is illustrated by comparing the uplink frequencies of broadband systems such as Teledesic and ACTS with the uplink frequencies of "big" Low-Earth-Orbit (LEO) systems such as Iridium, Globalstar, and ICO. Whereas the goal of big LEO systems is to provide services similar to those currently available from cellular providers, the objective of next-generation broadband systems is to offer wireless services similar to or exceeding those currently available from wired, fiber-based systems [10,11]. For example, the $2.048 \mathrm{Mbps}$ uplink data rate planned for Teledesic is roughly 40 times as fast as today's standard modems. To enable broadband services to mobile users, low-cost mobile units capable of transmitting and receiving signals at Ka-band must be developed. Because tunable dielectric devices may provide substantial improvements in performance, cost, and RF power-handling capability at Ka-band, as compared to existing technologies, devices which use these materials as the control elements may potentially play a major role in the evolution of broadband wireless systems. A summary of several satellite communication systems already deployed or under development is presented in Table 1.

Table 1. Summary of Several Satellite Communication Systems. Data taken from reference 6.

\begin{tabular}{|c|c|c|c|c|}
\hline System & Category & Services & $\begin{array}{l}\text { Uplink Data } \\
\text { Transmission } \\
\text { Rates (kbps) }\end{array}$ & $\begin{array}{l}\text { Mobile Uplink } \\
\text { Frequencies }\end{array}$ \\
\hline Iridium & Big LEO & $\begin{array}{l}\text { Voice, data, fax, paging, } \\
\text { messaging, and position } \\
\text { location. }\end{array}$ & $\begin{array}{l}2.4 / 4.8 \text { (voice) } \\
2.4 \text { (data) }\end{array}$ & $1616-1626.5 \mathrm{MHz}$ \\
\hline Globalstar & Big LEO & $\begin{array}{l}\text { Voice, data, fax, paging, } \\
\text { messaging, and position } \\
\text { location. }\end{array}$ & $\begin{array}{l}2.4 / 4.8 / 9.6 \\
\text { (voice); } 7.2 \\
\text { (data) }\end{array}$ & $1610-1626.5 \mathrm{MHz}$ \\
\hline ICO & Big LEO & $\begin{array}{l}\text { Voice, data, fax, and } \\
\text { paging. }\end{array}$ & $\begin{array}{c}4.8 \text { (voice); } 2.4 \\
\text { (data) }\end{array}$ & $2170-2200 \mathrm{MHz}$ \\
\hline ACTS & Broadband GEO & $\begin{array}{l}\text { Experimental platform for } \\
\text { data and video }\end{array}$ & Up to $622 \mathrm{Mbps}$ & $30 \mathrm{GHz}$ \\
\hline Teledesic & Broadband LEO & $\begin{array}{l}\text { High bandwidth data, } \\
\text { voice, fax, paging and } \\
\text { video. }\end{array}$ & $\begin{array}{l}16 \text { (voice); } 16 \\
\text { kbps }-2.048 \\
\text { Mbps (data) }\end{array}$ & $28.6-29.1 \mathrm{GHz}$ \\
\hline
\end{tabular}


The development of tunable dielectric components will play a major role in the development of devices which make the aforementioned goals possible. Beam steerable antennas, tunable filters, and tunable local oscillators can be made using conventional technologies such as semiconductor, ferrite, or mechanical tuning, but are plagued by one or more of the following problems: limited performance at the frequency of interest, prohibitively high cost, or lack of compatibility with other components of the communications system. Some of the characteristics which make tunable dielectric materials attractive for wireless communications are reasonably high Q's at microwave and millimeter-wave frequencies, planar structures which make them compatible with microstrip and fin line configurations, low dc power consumption, high RF power-handling capabilities, and low manufacturing cost. These characteristics can be advantageous in a wide variety of devices. In this chapter, we outline the general system requirements which must be considered for next-generation wireless systems and explain where tunable dielectric components could improve overall system performance. We then summarize the current status of tunable dielectric materials and correlate the microwave performance with materials properties and device configurations. Finally, the performance of specific prototype devices is presented.

\section{General System Considerations}

Next-generation wireless systems will require substantially higher data transmission rates than current systems provide, and rely more heavily on satellite communications to provide coverage to sparsely populated regions. Both of these trends attest to the need for commercial wireless systems with user-tosatellite links at substantially higher frequencies than are currently utilized. In order to achieve higher data transmission rates, larger bandwidths and more efficient use of the available bandwidth is necessary. Since the frequency spectrum is already crowded at frequencies up to $\mathrm{Ku}$-band $(12-18 \mathrm{GHz})$, it is imperative that systems which operate at K-band (18-26.5) and Ka-band (26.5-40 GHz) be developed because these are the lowest frequency bands at which sufficient bandwidth is available to support broadband applications. Next-generation wireless systems can be broadly categorized as point-to-point, where there is a line-of-sight pathway between the end user and the base station, or satellite-to-earth 
systems, where a series of LEO satellites communicate with earth stations or directly with the user [12]. Local Multipoint Distribution Services (LMDS) is a point-to-point system slated to operate at $25-31 \mathrm{GHz}$, with channel bandwidths ranging from $100 \mathrm{kHz}$ to $40 \mathrm{MHz}$ [7]. Satellite systems such as Teledesic will operate at user-to-satellite uplink and downlink frequencies of approximately 29 and $19 \mathrm{GHz}$. respectively, and other broadband services will also operate at K- and Ka-band frequencies [13]. The primary reasons for choosing these frequencies are the availability of larger bandwidths and relatively low atmospheric absorption (as compared to absorption at slightly lower or higher frequencies) [12].

The need for higher bandwidths and more efficient use of available bandwidth is illustrated by comparing the bandwidths and data transmission rates currently required for voice/audio applications with those required for emerging applications as shown in Table 2.

Table 2. Current and future applications for wireless communication systems, and bit rate requirements. Data taken from reference 1.

\begin{tabular}{lcc}
\hline \multicolumn{1}{c}{ Application } & $\begin{array}{c}\text { Anticipated Bit Rate } \\
\text { Requirements }\end{array}$ & Comments \\
\hline Voice/Audio & $8-256 \mathrm{kbps}$ & $\begin{array}{c}\text { Narrowband voice channels are } \\
\text { typically 30 } \mathrm{kHz}[14]\end{array}$ \\
Digital Data & $0.1-10 \mathrm{Mbps}$ & \\
Video Telephony & $64-384 \mathrm{kbps}$ & \\
Motion Video & $1.5-6 \mathrm{Mbps}$ & Up to 500-600 MHz of \\
Wireless Asynchronous Transfer & $10-20 \mathrm{Mbps}$ & $\begin{array}{c}\text { bandwidth required to support } \\
\text { service. }\end{array}$ \\
\hline
\end{tabular}

Although it is impossible to specify precise bandwidth requirements for the above applications, it is clear that substantially larger bandwidths will be required for these services than are currently being used for wireless voice telephony. The uncertainty in bandwidth requirements is due to the varying informationbit-per-bandwidth efficiencies of different modulation access and encoding techniques. The maximum data rates are arrived at by first involving Shannon's criteria, which states that a bandwidth of X Hertz allows for a maximum transmission of $2 \mathrm{X}$ independent, message-conveying signal amplitudes [15]. The number of bits represented by each signal can be further increased by utilizing modulation techniques, and increasingly complex modulation techniques are being implemented to reduce the bandwidth 
requirements. However, these techniques also decrease the range over which a signal can deviate from its desired amplitude and/or phase and still transmit information accurately. The primary techniques for supporting applications which require high data transmission rates are to increase the channel bandwidth or to specify more channels to support the application. Higher data transmission rates are also accomplished by utilizing amplitude and/or phase modulation to increase the number of bits which can be represented by each signal [8]. For example, three bits of information can be transmitted by a lone signal with eight $\left(=2^{3}\right)$ possible amplitude states. Likewise, signals in which the phase can be modulated into one of eight possible phase states (i.e., 45 degree increments) can also be used to represent three bits. In practice, the two techniques are combined into Quadrature Amplitude Modulation (QAM) schemes wherein both the signal amplitude and phase are modulated, thus data transmisșion rates are typically much higher than the bandwidth. To improve the bandwidth efficiency of low-cost user terminals, tunable control devices with high $Q$ values and RF power-handling capabilities at Ka-band are required; the control elements must encode the signal without introducing excessive distortion. Research is currently underway to establish whether tunable dielectric control elements will outperform semiconductor and ferrite devices in these applications.

\section{A. Hardware Requirements for High Bandwidth Systems at Ka-Band}

In order to transmit information, the signal-to-noise $(\mathrm{S} / \mathrm{N})$ and signal-to-interference $(\mathrm{S} / \mathrm{I})$ power levels of the transmitter-to-receiver link must be large enough to avoid excessive errors in the transmitted information. For digital systems, a more appropriate figure of merit is the bit-error-rate (BER), $E_{b} / N_{o}$, which is defined as the received information bit energy to noise energy density. The most probable sources of "noise" are background noise caused by precipitation, thermal noise created by the random motion of electrons, or the presence of interfering signals which arise from nearby wireless systems and intermodulation distortion. Although the maximum allowable bit energy rates for various systems depend on a number of factors such as the required accuracy of the transmitted information and complexity of modulation scheme (e.g., to achieve the same transmission accuracy, systems using higher QAM schemes require lower BER's than systems using less complex QAM schemes), the trend towards higher 
frequencies and lower BER requirements is unmistakable. Thus, novel hardware must be developed if these goals are to be met in a cost-effective manner. An example which illustrates the simultaneous need for higher bandwidth and smaller BER's is video transmission, which requires $10^{-6}$ or lower BER values. By comparison, BER values as high as $10^{-2}$ are acceptable for voice telephony [12]. In addition to requiring larger bandwidth, higher carrier frequencies, and more complex modulation schemes, nextgeneration applications will also require substantially lower BER values (e.g., 10-12) than those currently required for most voice applications.

Achieving low BER values at higher frequencies and over larger bandwidths will require substantial hardware improvements. The situation is further complicated because simply increasing the bandwidth does not result in a proportionate increase in the transmission rate of a given channel, $\mathrm{C}$, since the signalto-noise ratio decreases as the bandwidth becomes larger, as illustrated by [15]:

$$
C=B \log \left(1+\frac{S}{k T B}\right)
$$

where $\mathrm{C}$ is the channel capacity (bits/second), B is the bandwidth $(\mathrm{Hz}), \mathrm{S}$ is the power of the received signal, $\mathrm{k}$ is Boltzmann's constant, and $\mathrm{T}$ is the temperature. Equation (1) illustrates that at $\mathrm{K}$ - and $\mathrm{Ka}$-band frequencies, large bandwidth systems will have to transmit at higher power levels than current cellular and PCS systems in order to compensate for the higher noise levels inherent in large bandwidth systems. In addition, precipitation is a major source of attenuation at these frequencies, and utilizing higher RF power levels is one technique to overcome this attenuation. The power-generating capabilities of current cellular and PCS systems are generally limited by the dynamic range of amplifiers; as the power level increases, the amplifiers become nonlinear, which distorts the waveform of the signal and results in a rapid deterioration in BER rate. Furthermore, the RF power-handling capabilities of many conventional tunable and nontunable passive semiconductor components are questionable for the high power levels requirements of next-generation systems. 
A potentially attractive means of achieving the required BER values for video and other high data transmission rate applications without drastically raising the transmitter power levels is to introduce cryocooling into the system. On the receiver end of the RF link, cooling the receiver front end (specifically, the bandpass filter and first-stage amplifier) substantially lowers the intrinsic noise power, noise floor, and noise figure of the system. Cooling the first-stage amplifier to temperatures of 100-175 K also increases the dynamic range, thus the amplifiers can be operated at higher gain levels, which also lowers the BER values $[16,17]$.

For wireless systems with high usage, co-channel interference is the dominant source of BER degradation. Co-channel interference arises when one or more undesired signals have frequencies within the passband of the desired signal, and are transmitted to the receiver. The primary sources of co-channel interference are mobile users in nearby cells operating at frequencies which overlap with those in the desired cell [18], and third order intermodulation products caused by mounting the transmit and receive antennas in close proximity on base station towers. A highly effective means of reducing co-channel interference is to replace conventional antennas with beam-steerable, adaptive phased array antennas. Adaptive beam steering minimizes co-channel interference because narrower beamwidths can be used and nulls can be directed towards interfering signals, thus dramatically boosting the signal-to-interference ratio. The narrower beamwidth also increases the antenna range since the beam power is compressed into a smaller radius and thus extends further.

Phased array antennas are also used to adjust the phase and gain in an adaptive manner, thus enabling the gain and directivity of the antenna to be adjusted in real time. The use of beam-steerable, adaptive phased array antennas may not only be helpful, but also essential for large bandwidth applications at Ka-band. At frequencies above $2 \mathrm{GHz}$, precipitation is often the dominant loss mechanism in the user-to-satellite link, and adaptive control of the antenna gain may provide a means of compensating for rapidly changing attenuation due to varying weather conditions. Adaptive control over system parameters such as antenna gain and beam direction is required in order to offset this degradation and maintain acceptable signal-to- 
noise ratios [18]. Although phased array antennas are well known, they are prohibitively expensive to build, and thus used primarily for high-cost military applications. A large portion of the steerable-beam antenna cost is due to the phase shifters used to steer the beams, which may be over $\$ 1000$ per transmit/ received module. The need for a novel, low-cost phase shifter technology is illustrated by noting that the antenna beamwidth is inversely proportional to the number of radiating elements, thus hundreds to tens of thousands of phase shifters and radiating elements may be required for a narrow-beam phased-array antenna. For example, a 6 degree beamwidth antenna requires several hundred phase shifters, and many applications require substantially narrower beamwidths. Clearly, the cost associated with current phase shifters is unacceptable for commercial applications [19], and a break-through in phase shifter technology is required if the goal of a low-cost phased array antenna is to be achieved.

The cost and performance requirements of the user terminals of next-generation wireless systems are daunting. Modulating, transmitting, receiving, and demodulating signals at Ka-band frequencies over large bandwidths will require major advances in active and passive device development. Tunable devices will have a more predominant role at Ka-band than at L-band, primarily because of the need for adaptive beam steering and complex encoding techniques. The development of tunable devices is especially challenging because the tunable devices are intrinsically nonlinear, yet they must carry out their functions without introducing excessive signal distortion. Furthermore, video and data file transfer applications require substantially lower BER values than current voice applications, and these highly stringent standard will be imposed while simultaneously increasing the carrier frequencies by a factor of 10 or more, from L-band to Ka-band. Semiconductor switching devices such as pin diodes and field effect transistors, as well as analog tuning devices such as varactors, perform well at $2 \mathrm{GHz}$, but are not easily scaled to higher frequency operation due to fundamental materials limitations. New devices and materials are required to meet the performance and cost goals. Novel devices such as steerable-beam antennas, tunable filters, and tunable oscillators based on voltage-tunable paraelectric materials have the potential to fill the need for high-performance, tunable passive devices which can be implemented into Ka-band systems at low cost. 


\section{Development of Tunable Thin Film Dielectric Materials and Devices}

The interest in tunable dielectrics for microwave and millimeter-wave applications has been fueled by the recent explosion in wireless communications. The concept of exploiting the voltage-dependent dielectric constant of ferroelectric and tunable dielectric materials such as BSTO for microwave tuning applications has been discussed for more than 30 years [20]. However, the original idea of making tunable devices from bulk ferroelectric materials was not pursued aggressively primarily because it is difficult to design bulk devices which have both the low capacitance values required for microwave applications concomitantly with large tunabilities at moderate dc voltage levels (i.e. tens of volts). Specifically, matching the varactor reactance, $X_{c}=1 / \omega C$, to the impedance of the rest of the circuit usually requires capacitance values less than 10 picofarads $(\mathrm{pF})$. For example, a varactor designed for $50 \Omega$ characteristic impedance at $2 \mathrm{GHz}$ must have a capacitance of $1.6 \mathrm{pF}$; higher or lower capacitance values will cause signal reflections because of impedance mismatch. Since the desired capacitance value for impedancematched circuits is inversely proportional to frequency, the need for even lower capacitance varactors at Ka-band is obvious. Furthermore, there are several applications where signal reflections are intentionally designed into the circuit, and these applications call for even lower capacitance values than would be dictated by an impedance-matched circuit. For example, in tunable microstrip filters the varactor is located at positions where the RF voltage is maximized, such as the end of a one-half wavelength resonator. In this configuration, the varactor essentially replaces the open circuit capacitance of the resonator end with a variable capacitance [21].

To appreciate the capabilities and potential of tunable devices based on tunable dielectric thin films, it is important to understand the competing technologies: semiconductors and ferrites. These technologies do not meet the requirements of low losses, low distortion, ease of integration into larger systems, and inexpensive manufacturing cost for several reasons. Schematic diagrams of a semiconductor $\mathrm{p}-\mathrm{n}$ junction and ferrite toroid are shown in Figure 2. Semiconductor varactors, while widely used for low frequency 
applications, suffer $\mathrm{Q}$ degradation due to series resistance losses. This degradation is proportional to frequency, and often limits the device performance at frequencies above approximately $2 \mathrm{GHz}$ [22-24]. A Schottky barrier semiconductor varactor is comprised of a p-n junction, and the capacitance is controlled by varying the reverse bias voltage, which in turn controls the junction width and thus capacitance [25].

To achieve high tunability, the p-n layers should be lightly doped so that the width of the depletion region is substantially altered with moderate changes in bias voltage. However, since the undepleted portion of the semiconductor layer also serves as one of the electrodes, lightly doped layers are resistive and are the source of excessive losses and $\mathrm{Q}$ degradation at microwave frequencies.

Another problem of semiconductor varactors is poor RF power-handling capability. Low capacitance varactors are achieved by decreasing the capacitor area, and Ka-band semiconductor varactors may have areas as small as $2.5 \times 10^{-7} \mathrm{~cm}^{2}$. Bearing in mind that typical space charge depletion widths are typically 1-5 $\mu \mathrm{m}$, the amount of RF power which can be transmitted through such a small volume without substantial signal distortion is limited to values less than one milliwatt. Although tradeoffs can be made in terms of capacitance, tunability, Q, and power-handling capability which enable semiconductor varactors to operate at frequencies above $500 \mathrm{GHz}$ [26], it is difficult to design a varactor which simultaneously meets the requirements for high $\mathrm{Q}$, high power-handling capability, and low capacitance necessary for Ka-band applications. Closely related to varactor diodes, are PIN diodes. They have substantially higher power-handling capabilities than varactor diodes because the RF voltage is distributed across an insulating region which is much larger than the varactor space charge region [27]. However, PIN diodes are RF switching devices and thus incapable of analog tuning [28]. Since the primary objective of this chapter is to summarize the status of tunable dielectric materials for analog tuning applications, comparisons between devices which use tunable dielectric materials and PIN diodes as the control elements are usually not appropriate. 


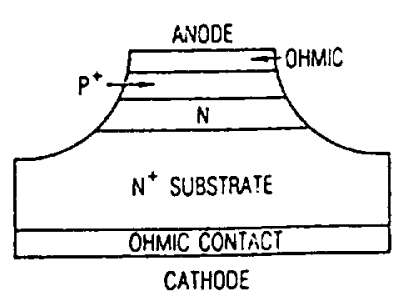

(a)

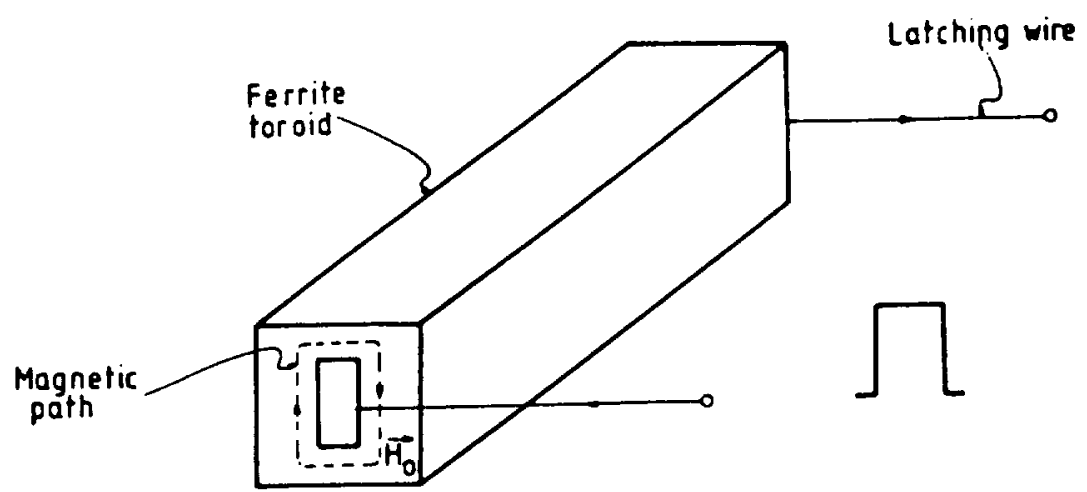

(b)

Figure 2.-Schematic diagram of conventional analog tuning technologies; (a) Mesa structure of $p+n$ semiconductor varactor ${ }^{26}$ (Reprinted by permission of IEEE Press). (b) Magnetized ferrite toroid ${ }^{102}$ (Reprinted by permission of Artech House).

In contrast to semiconductors, ferrite control devices are capable of transmitting substantially higher RF power levels and have low losses, particularly above $3 \mathrm{GHz}$ [29]. However, ferrite tunable devices such as phase shifters and filters require expensive, cumbersome, and power-consuming tuning circuitry. For example, the tuning circuitry of a voltage-controlled oscillator with ferrite tuning may require on the order of $12 \mathrm{~V}$ and $50 \mathrm{~mA}$ to tune the circuit and maintain it at a constant temperature [30]. Since active devices such as semiconductor transistors typically operate at $1-5 \mathrm{~V}$ and less than one milliamp of current, ferrite tuning is the dominant source of dc power consumption in these circuits. In addition, tunable ferrite devices, either in bulk or thin film form, are difficult to integrate with microstrip, stripline and finline circuits because of the nature of the tuning circuitry (e.g., an induction coil) required for their implementation [31,32]. At millimeter-wave frequencies, ferrites become more attractive because the device size decreases with increasing frequency, thus the drive powers for the tuning circuitry also decrease. However, because of integration and cost considerations, we believe that ferrite tuning is unlikely to play a large role in Ka-band commercial applications such as steerable-beam antennas and tunable filters. 
Although the BSTO materials cited in this article are often classified under the general heading of "ferroelectrics," the best microwave performance to-date has been observed for materials in the paraelectric rather than ferroelectric state. Although current paraelectric device development is focused on thin films, a great deal of information regarding the baseline microwave properties of perovskites has been obtained through bulk studies. For example, from studies of the high frequency $(3 \mathrm{GHz})$ dielectric properties of bulk BSTO $(\mathrm{Ba}: \mathrm{Sr}=73: 27)$ samples, high values of $\tan \delta$ have been directly attributed to the ferroelectric state by demonstrating that $\tan \delta$ was substantially higher at temperatures below $T_{c}$ than above it [33]. The room temperature dielectric constant of these samples was tuned from 5300 at $0 \mathrm{~V}$ bias to $\sim 2000$ when a dc electric field of $8.4 \mathrm{kV} / \mathrm{cm}$ was applied. No dispersion in dielectric constant as a function of frequency was observed, and the Curie point shifted to higher temperatures with increasing bias voltage. At $25^{\circ} \mathrm{C}$ and $3 \mathrm{GHz}$, tan $\delta$ ranged from $0.12-0.08$ depending on dc bias. Tan $\delta$ values were substantially higher at temperatures below the Curie temperature, suggesting that the ferroelectric phase introduces substantial intrinsic dielectric loss at microwave frequencies.

Correlation between the presence of the ferroelectric phase and high microwave losses was reinforced by subsequent measurements on piezoelectric crystals. Measurements taken at $0.5-2.0 \mathrm{GHz}$ on a $\left(\mathrm{Pb}_{0.94} \mathrm{Sr}_{0.06}\right)\left(\mathrm{Zr}_{0.53} \mathrm{Ti}_{0.47}\right) \mathrm{O}_{3}$ (PSZT) ceramic showed a gradual drop in $\varepsilon_{\mathrm{r}}$ and sharp increase in tan $\delta$ with increasing frequency [34]. At $25^{\circ} \mathrm{C}$ and $2 \mathrm{GHz}, \varepsilon_{\mathrm{r}}$ and tan $\delta$ were 800 and 0.42 , respectively. By adjusting the composition to bring the Curie point below room temperature, dispersion in $\varepsilon_{\mathrm{r}}$ and $\tan \delta$ was $\operatorname{largely}$ suppressed. At $25^{\circ} \mathrm{C}$ and $2 \mathrm{GHz}, \varepsilon_{\mathrm{r}}$ and $\tan \delta$ for a $\left(\mathrm{Pb}_{0.35} \mathrm{Sr}_{0.65}\right) \mathrm{TiO}_{3}$ ceramic were 1400 and 0.04 , respectively. The conclusion was that the frequency dispersion in $\varepsilon_{r}$ and high $\tan \delta$ values of the PSZT sample were due to ferroelectric domain wall motion, and these types of losses are intrinsic to all piezoelectric materials.

Considerable effort has been expended to understand the dominant loss mechanisms in single-phase paraelectric ceramics. Rupprecht, Bell, and Silverman published a series of articles which documented the $22 \mathrm{GHz}$ losses in bulk STO and BSTO (various $\mathrm{Ba}: \mathrm{Sr}$ ratios) as a function of temperature [35-37]. The 
Cavity measurements at 4.5 and $10.0 \mathrm{GHz}$ showed no change in $\varepsilon_{\mathrm{r}}$ or tuning from the $1 \mathrm{kHz}$ data, and $\tan \delta$ at these frequencies was 0.007 and 0.012 , respectively. In contrast to the simplicity of the processing technique, the microstructure/microwave property correlation of these materials appears to be complex, and unraveling this correlation may be a significant step towards optimizing paraelectric materials (thick as well as thin film) for microwave tuning applications. In addition to lowering the dielectric loss of tunable materials, decreased $\varepsilon_{\mathrm{r}}$ values minimize the metallization loss, which frequently is the dominant loss mechanism when high $\varepsilon_{\mathrm{r}}$ substrates are used in planar microwave devices $[51,52]$. These materials are extremely promising for a variety of room-temperature distributed-element devices such as phase shifters and electronically controlled filters based on bulk and thick film tunable dielectric materials [53-54].

\section{A. Thin Film Optimization for Microwave Tuning Applications}

Because of the need for low capacitance and low loss for tunable microstrip, stripline, and fin line filters and phase shifters, there is substantial interest in thin film tunable dielectric materials. Thin film devices have configurations which are compatible with planar microwave circuits, and thus are preferred to bulk devices. Varactors fabricated using thin films can be designed to have capacitance values in the ranges required for microwave circuitry, with tuning dc voltage levels ranging from zero to several hundred volts.

\section{B. Tunable Dielectric Films as Microwave Varactors}

The advantages of using ferroelectric materials for tunable microwave components are well established [55-57]. Originally, only bulk or thick film ferroelectrics were used as the tuning elements because the quality of thin films achievable at the time was inadequate for microwave applications. In retrospect, it appears that the large grain boundary/grain volume ratio of polycrystalline thin films was a major impediment to high tunability in planar varactors, since grain boundary phases lack the crystalline quality required for high tunability. Recent improvements in deposition techniques have yielded thin films with epitaxial microstructures, resulting in much larger tunabilities than were previously reported. STO and BSTO films deposited at temperatures ranging from $600-800^{\circ} \mathrm{C}$ displayed substantially higher $\varepsilon_{\mathrm{r}}$ values 
and tunabilities at microwave frequencies [58-60]. Using a structure wherein the ferroelectric film was located at the RF voltage maximum of the odd modes of a two-port resonant structure, Galt et al., [59] demonstrated that laser ablated STO films have no discernable dispersion in dielectric constant, tuning, or $\tan \delta$ at 6,13 , and $20 \mathrm{GHz}$. The measurements were taken at $77 \mathrm{~K}$. The lack of frequency dependence on the dielectric properties of the films was attributed to their epitaxial microstructure.

\section{Parallel Plate STO and BSTO Varactors}

Much of the initial work aimed at optimizing paraelectric thin films for tunable microwave devices was performed using parallel plate structures where the paraelectric film is sandwiched between two conductor layers. Parallel plate and planar varactor configurations are illustrated in Figure 3. The parallel plate configuration enables capacitance, $\varepsilon_{\mathbf{r}}$, tan $\delta$, and tuning to be measured directly using simple capacitance techniques at low frequencies (i.e., $1 \mathrm{MHz}$ ) [6I-64]. From a device standpoint, this structure is advantageous because for thin (e.g., $<1 \mu \mathrm{m}$ ) films, tuning is accomplished with dc voltage levels below $5 \mathrm{~V}$, thus making the control bias levels compatible with the bias levels used in semiconductor logic devices. The tuning voltages required for parallel plate structures are much lower than the voltages required for planar structures because the separation between conducting layers is much smaller (i.e. $<1 \mu \mathrm{m}$ versus 5-20 $\mu \mathrm{m}$ for planar structures). Since tuning is a function of the dc electric field strength, and large electric fields can be generated with relatively small voltages in parallel plate structures, the required voltages are modest.

Measurements of parallel plate Au/STO/YBCO capacitors showed that highly epitaxial STO films provide substantial capacitance tuning ranges [61]. Subsequent data indicated the Curie temperature of STO and BSTO films was shifted to higher temperatures by increasing the dc bias [62,64], similar to the effect observed in bulk BSTO. The bias dependence on the Curie point was most pronounced in highly crystalline, high $\varepsilon_{\mathrm{r}}$ films which displayed the highest tunabilities. It was also established that tuning in thin films is suppressed by the presence of trace amounts of second phases [63], and that STO films deposited on YBCO are susceptible to electrical shorting through the STO layer caused by the roughness of the underlying YBCO layer [65]. 
Despite the difficulties involved in measuring the microwave properties of parallel plate ferroelectric varactors, some data exist. Early work by Carroll et al., demonstrated that the microwave loss of $\mathrm{Ag} / \mathrm{BSTO}(50 / 50) / \mathrm{Pt} / \mathrm{MgO}$ structures was dominated by electrode losses [66]. Later work by the same group established that parallel plate varactors with highly crystalline, (100) oriented, $0.5 \mu \mathrm{m}$ thick BSTO (80/20) layers deposited using laser deposition had $40 \%$ tunability with five volts dc bias at $2 \mathrm{GHz}$, and tan $\delta$ ranged from $0.067-0.10$ [67]. The extent of tunability is defined as $\left(C_{v}-C_{0}\right) / C_{0}$ where $C_{0}$ and $C_{v}$

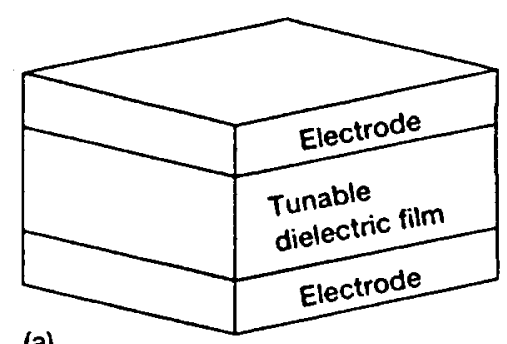

(a)

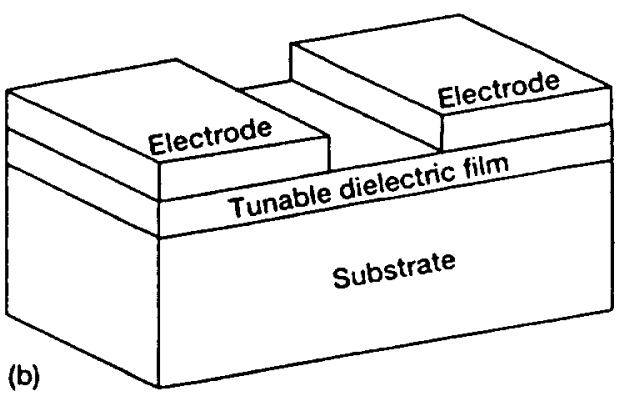

Figure 3.-Schematic diagrams. (a) Parallel plate paraelectric varactor configuration. (b) Planar varactor configuration.

are the capacitence values at zero and maximum dc voltage levels. Williamson et al, measured the dielectric properties of parallel plate $0.5 \mu \mathrm{m}$ thick PZT capacitors deposited using sol-gel processing at frequencies up to $15 \mathrm{GHz}$, and observed a sharp drop in $\varepsilon_{\mathrm{r}}$ and increase in $\tan \delta$ at $1.3 \mathrm{GHz}$ for compositions where the rhombohedral phase was stable [68]. This behavior was attributed to the frequency of the ac electric fields exceeding the speed of domain wall movement. By contrast, compositions for which the ferroelectric tetragonal phase was stable showed higher $\varepsilon_{\mathrm{r}}$, lower $\tan \delta$, and less dispersion from 1-15 GHz. Chivukula et al., measured the dielectric properties of parallel plate BSTO (50/50) and PZT (40/60) films deposited using sol-gel processing and reported a roll-off in $\varepsilon_{\mathrm{r}}$ above 1 
$\mathrm{GHz}$ due to series resistance in the bottom electrode [69]. After correcting for the electrode resistance, no dispersion in dielectric data was observed up to $6 \mathrm{GHz}$. The authors attributed the lack of dispersion to the small $(10 \mathrm{~nm})$ grain size of the films, which suppressed domain wall formation. Despite the advantage of tuning with low dc voltages, the use of ferroelectric varactors with parallel plate configurations for microwave applications is inhibited by series electrode losses in the bottom electrode and the difficulty of forming smooth, highly crystalline ferroelectric films on conducting layers.

\section{Planar Electrode Structures}

Most tunable microwave resonators and phase shifters which use paraelectric films to tune the frequency or phase response use planar electrode configurations to integrate the ferroelectric films into the devices. Planar varactors are typically fabricated by depositing tunable dielectric films on dielectric substrates using laser ablation, sol-gel, chemical vapor deposition, or physical sputtering, followed by metal electrode deposition. This technique is used to fabricate monolithic devices, or alternatively, arrays of varactors are formed by patterning the metallization into gap or interdigital structures and subsequently dicing the substrate to form individual varactors. The varactors are then bonded into the circuit as discrete devices. Early work showed that planar tuning configurations are more compatible with planar microwave circuitry $[59,60,70,71]$. From a design standpoint, planar structures are advantageous because they can be readily designed to have capacitance values which provide good impedance matching to the rest of the circuit, thus minimizing the fraction of microwave energy reflected at the conductor/varactor junction. A second advantage of the planar configuration is that the device capacitance can be varied over a wide range by adjusting the tunable dielectric film thickness, which also allows for control over the distribution of microwave energy propagating in the film and low $\varepsilon_{\mathrm{r}}$, low $\tan \delta$ substrates such as $\mathrm{LaAlO}_{3}$ and $\mathrm{MgO}$.

This allows for trade-offs between tuning and $\tan \delta$ simply by adjusting the film thickness. Third, the large gap size of low-capacitance planar varactors simplifies design and fabrication considerations.

For tuning applications, both tunability and $\tan \delta$ must be considered when comparing the relative merits of different film compositions and varactor configurations. Comparing different film compositions, 
processing techniques and varactor configurations can be difficult and misleading if only the tuning or $\tan \delta$ of the film are reported. A figure of merit which provides a better comparison between various films is the $\mathrm{K}$-factor, defined as the tunability/tan $\delta(0 \mathrm{~V})$, and is given by:

$$
\mathrm{K}=\frac{\mathrm{C}_{0}-\mathrm{C}_{\mathrm{v}}}{\mathrm{C}_{0} \tan \delta_{0}}
$$

where $\tan \delta$ is measured with no dc bias.

While the $\mathrm{K}$ factor provides a quantitative measurement of film quality, it does not necessarily follow that films with the highest $\mathrm{K}$ factors are the most useful for devices. In application such as phase shifters and filters, minimal change in $\tan \delta$ as a function of bias is also important. The $\mathrm{K}$ factor of STO and BSTO thin films is highly sensitive to the substrate type, film deposition parameters (e.g., $\mathrm{O}_{2}$ atmosphere, deposition temperature, etc.), and post-deposition processing (e.g., high-temperature annealing). High tunability with modest $\mathrm{dc}$ voltage levels are obtained using planar configurations if the paraelectric films maintain in-plane epitaxy with the substrate and strain is minimal [65,72]. Tuning and tan $\delta$ for BST and STO films with these characteristics are shown in Figures 4 and 5, respectively. The high tunabilities of these films are attributed in large part to their high dielectric constants; using conformal mapping techniques $[73,74]$, room temperature $\varepsilon_{\mathrm{r}}$ values of $1500-2500$ for nominally $0.4 \mu \mathrm{m}$ thick BSTO (40/60) films, and $77 \mathrm{~K} \varepsilon_{\mathrm{r}}$ values of $3000-6000$ for $0.2-1.0 \mu \mathrm{m}$ thick STO films, were calculated. By comparison, $\varepsilon_{\mathrm{r}}$ values of polycrystalline BSTO and STO films rarely exceed 800 [75]. Interestingly, the $\varepsilon_{\mathrm{r}}$ values for the STO thin films at $77 \mathrm{~K}$ are higher than those of bulk, single crystal STO [76]. The reasons for this behavior are unclear.

Planar varactor configurations are also advantageous because the quality of tunable dielectric films deposited directly on dielectric substrates is much better than that of films deposited on metal-coated substrates. Films deposited directly on chemically unreactive, lattice-matched substrates such as $\mathrm{LaAlO}_{3}$ and $\mathrm{NdGaO}_{3}$ typically have the aforementioned high $\varepsilon_{\mathrm{r}}$ values and tunabilities, and atomic force 
microscopy and $x$-ray diffraction measurements indicate the as-deposited films are comprised of 50-70 $\mathrm{nm}$ grains which are epitaxially oriented relative the substrate, with typical rms surface roughness values of $0.3-0.5 \mathrm{~nm}[67,77]$. Because the substrate/film interface is chemically stable, deposition of tunable dielectric films directly on dielectric substrates enables the additional option of post-annealing the films at higher temperatures as a means of improving the electrical performance. Knauss et al, demonstrated that post-annealing BSTO thin films on LAO substrates at $900^{\circ} \mathrm{C}$ substantially decreased strain in the ferroelectric films, which led to higher tunabilities and $\varepsilon_{\mathrm{r}}$ versus temperature profiles similar to those observed in bulk materials [78]. Al-Shareef et al,and Raymond et al, demonstrated that increasing the post-annealing temperatures of BSTO and STO films to $1100^{\circ} \mathrm{C}$ caused substantial increases in grain size, $\varepsilon_{\mathrm{r}}$, and tunability $[79,80]$. Later work has demonstrated that BSTO and STO films deposited on $\mathrm{LaAlO}_{3}$ substrates benefit from post-annealing temperatures as high as $1200^{\circ} \mathrm{C}$, with the film surfaces adopting highly terraced, large-grained morphologies (Figs. 6 and 7). Post-annealing causes simultaneous

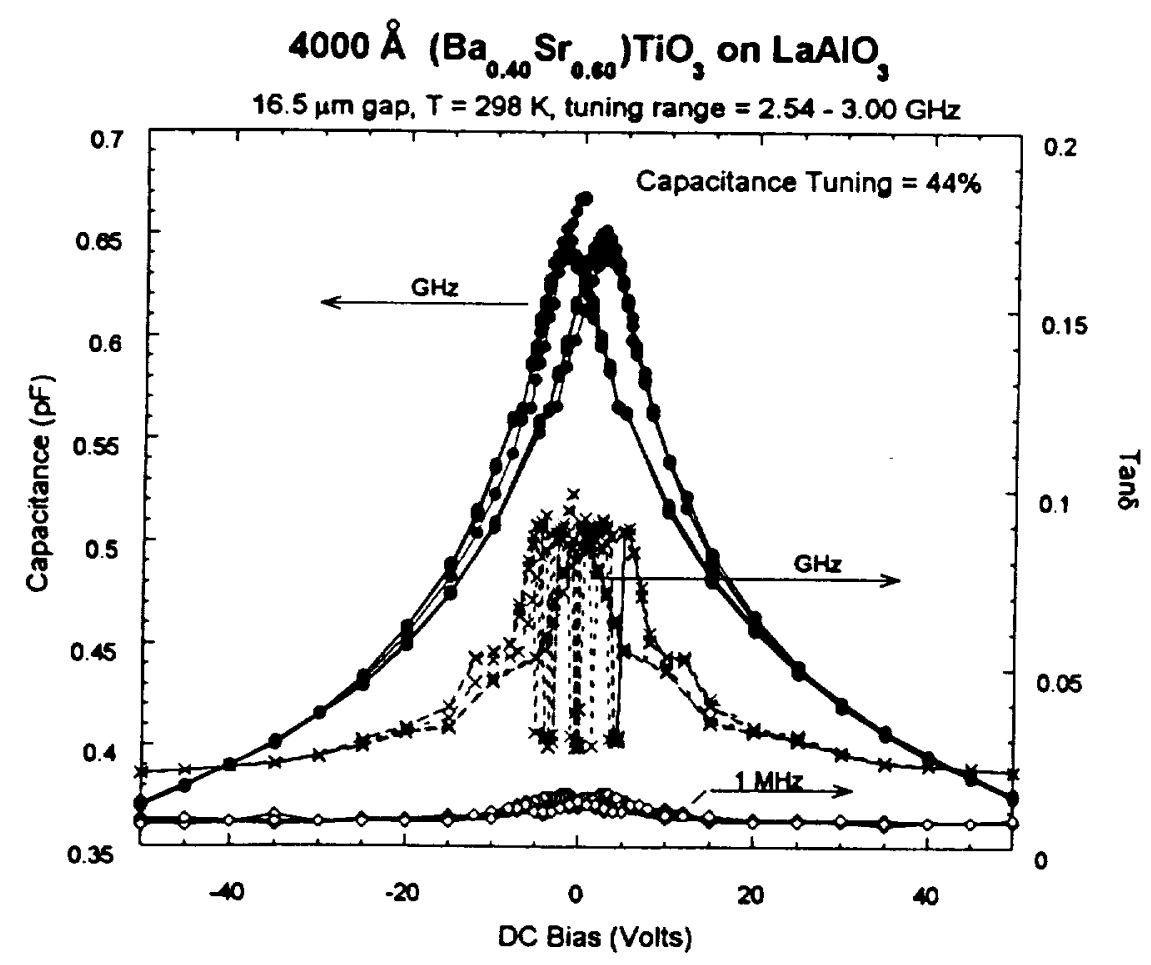

Figure 4.-Capacitance and $\tan \delta$ of $0.4 \mathrm{~mm}$ BSTO (40/60) interdigital varactor with $16.5 \mathrm{~mm}$ gap, data taken at $298 \mathrm{~K}$. The resonant frequency of the twoport circuit was tuned from 2.54-3.00 GHz by the dc bias, and the dc voltage was scanned over the entire range four times. $50 \mathrm{~V}$ dc bias corresponds to an electric field of $3.03 \times 10^{4} \mathrm{~V} / \mathrm{cm}$. Data courtesy of SCT, Inc. 


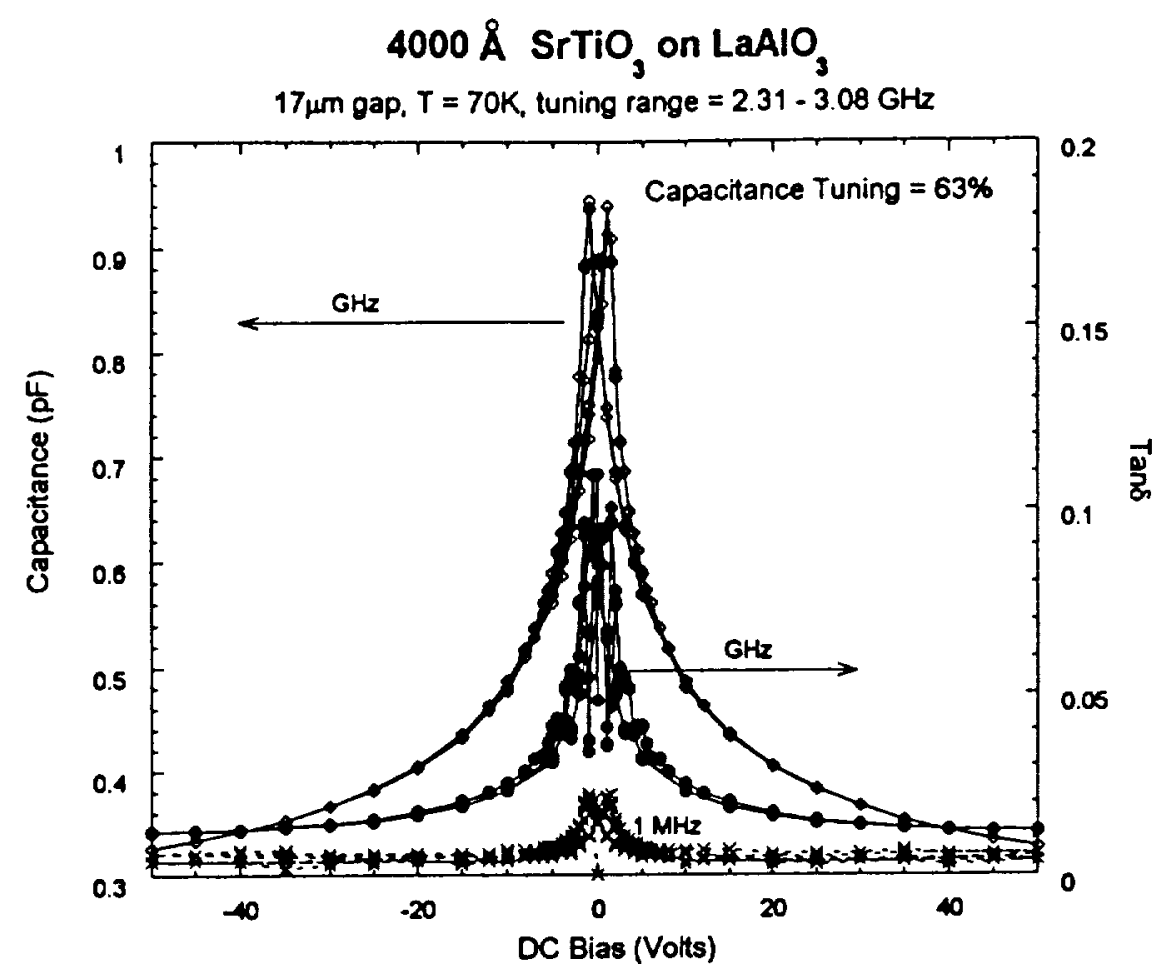

Figure 5.-Capacitance and $\tan \delta$ of $0.4 \mathrm{~mm}$ STO interdigital varactor with $17 \mathrm{~mm}$ gap, data taken at $70 \mathrm{~K}$. The resonant frequency of the two-port circuit was tuned from $2.31-3.08 \mathrm{GHz}$ by the dc bias, and the dc voltage was scanned over the entire range four times. $50 \mathrm{~V}$ dc bias corresponds to an electric field of $2.94 \times 10^{4} \mathrm{~V} / \mathrm{cm}$. Data courtesy of SCT, Inc.

increases in $\varepsilon_{r}$, tunability, and tan $\delta$. The $\mathrm{K}$ factors of the films are usually improved by the post-annealing step despite the higher $\tan \delta$ values.

It's apparent that the $\mathrm{K}$ factors of tunable dielectric varactors are highly dependent on the crystallinity, strain, and roughness of the films as well as film thickness and varactor geometry. Because the tunable dielectric films used for coplanar varactors are deposited directly on insulating substrates, more processing options are available to optimize film quality than for films deposited on normal metal layers such as $\mathrm{Ag}, \mathrm{Au}$, and $\mathrm{Pt}$. Hence the microwave losses of planar varactors are much lower and the $\mathrm{K}$-factors are higher than those of parallel plate varactors. While it's possible that advances in bottom layer metallization using conductive oxides may improve the performance of parallel plate varactors, problems such as minimizing the roughness and electrical resistance of the bottom electrode, and developing varactors with the low capacitance values required for microwave applications, must be overcome. 


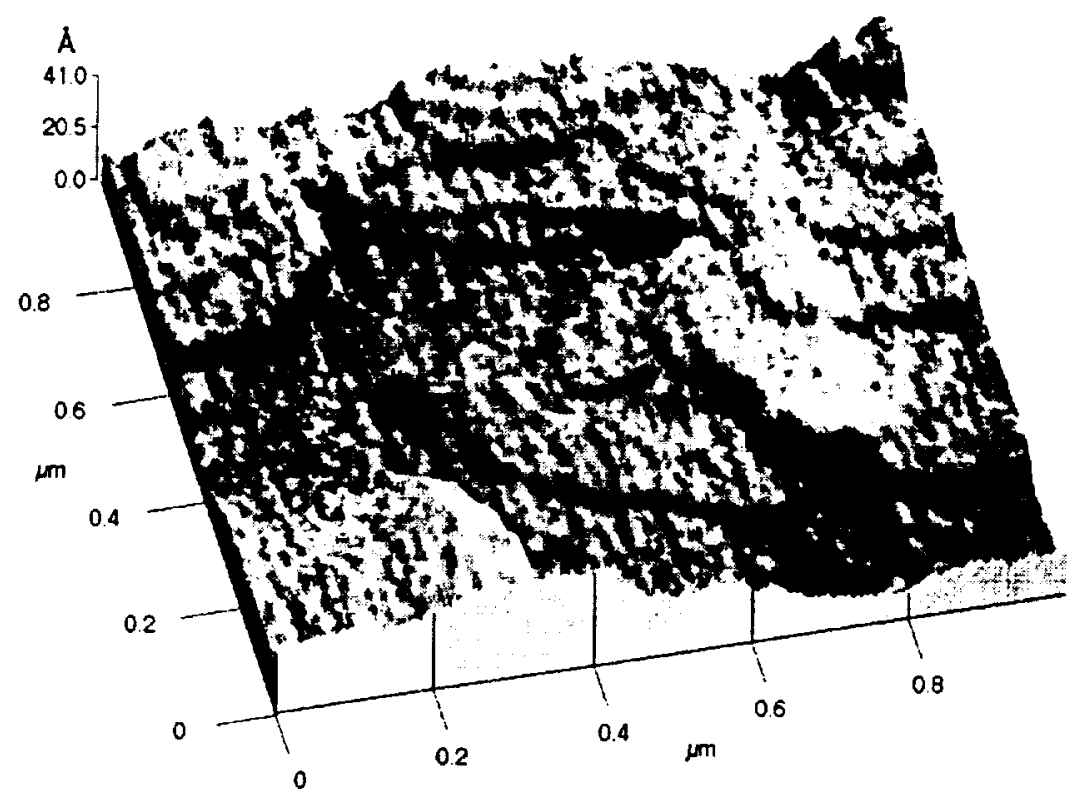

Figure 6.-Atomic Force Microscopy image of $0.4 \mathrm{~mm}$ BSTO film on $\mathrm{LaAlO}_{3}$ substate. The film was deposited using laser ablation at a substrate temperature of $750^{\circ} \mathrm{C}$, then post-annealed in an oxygen tube furnace at $1080^{\circ} \mathrm{C}$ for seven hours.

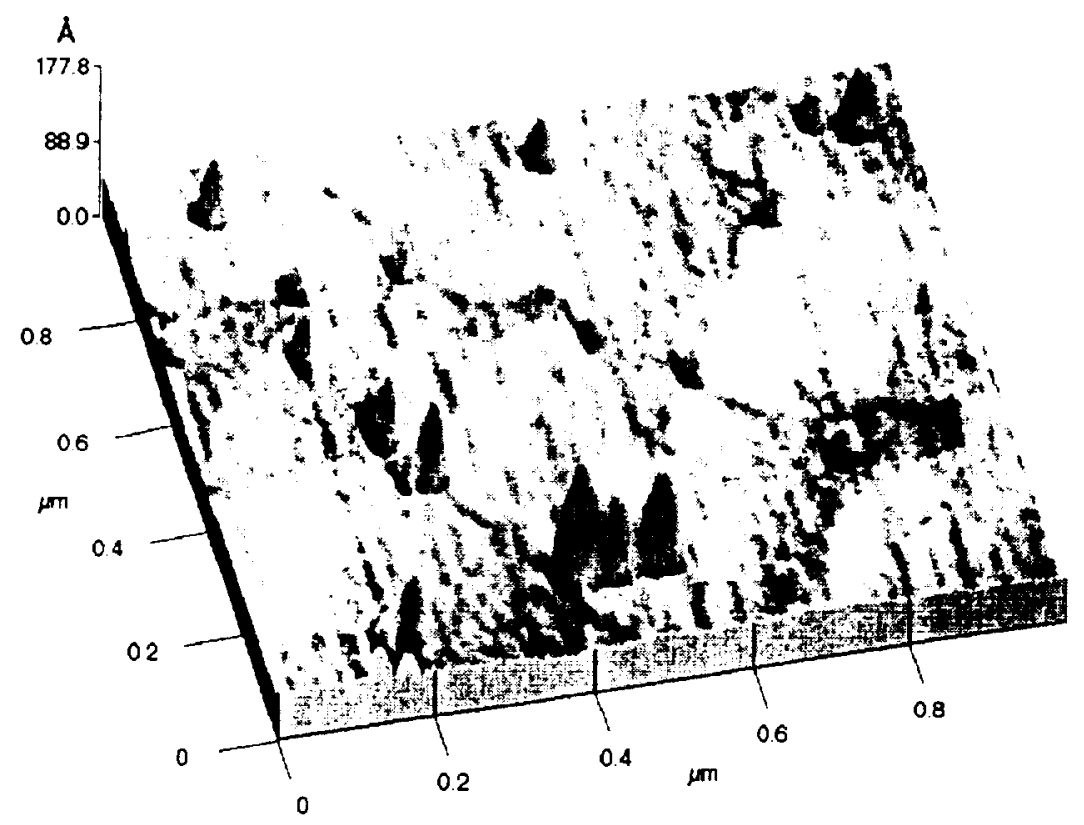

Figure 7.-Atomic Force Microscopy image of $0.4 \mathrm{~mm}$ STO (40/60) film on $\mathrm{LaAlO}_{3}$ substrate. The film was deposited using laser ablation at a substrate temperature of $750^{\circ} \mathrm{C}$, then post-annealed in an oxygen tube furnace at $1080^{\circ} \mathrm{C}$ for seven hours. 


\section{Hysteresis}

A problem which is prevalent in both planar and parallel plate paraelectric devices is hysteresis. The form of capacitance hysteresis which is most troublesome for microwave applications is the inability of the varactor to reproducibly adopt a specific capacitance for a specific dc voltage when the dc voltage is rastered across its tuning range. Examples of capacitive hysteresis in BSTO and STO varactors are evident in Figures 4 and 5. This problem must be overcome in order for these devices to become commercially acceptable because most of the applications outlined in this article cannot tolerate hysteresis. Phased array antennas require precise correlation between tuning voltage and phase shift, and capacitive hysteresis in the tuning elements will cause unacceptable degradation of the beam quality. Tunable filters have tight center frequency, bandwidth, in-band insertion loss, and out-of-band rejection loss specifications. The inability to precisely control the varactor capacitance will result in unacceptably large deviations from the desired device performance.

Understanding the origins of hysteresis is the first step towards minimizing it. Ferroelectric films are inherently hysteretic $[81,82]$, thus the presence of ferroelectric phases is to be avoided. The presence of hysteresis, together with large dielectric losses, are the primary reasons the compositions and processing conditions of tunable dielectric films are chosen so as to favor formation of paraelectric rather than ferroelectric phases. Film microstructure also appears to have an impact on hysteresis $[63,83]$. For STO and BSTO films, substantial reduction in hysteresis has been obtained by choosing deposition conditions, substrate type, and post-anneal conditions so as to promote the formation of large-grained, highly epitaxial films. Another parameter which may influence hysteresis is the electrode/film interface. Since the work functions of the two films differ, and there is an abrupt termination of the tunable dielectric film, it's plausible that the interface would be a source of hysteresis [84-86]. The abruptness and likely impact of the interface is most pronounced when the electrodes are comprised of normal metals such as $\mathrm{Au} / \mathrm{Ti}$, as compared to lattice-matched conducting-oxide electrodes. Obviously, more work is needed to understand the different sources of hysteresis and the relative extent to which each source contributes to the overall hysteresis level. 


\section{Microwave Power-Handling Capability}

One of the most attractive features of tunable dielectric devices is their ability to transmit high microwave power levels without causing unacceptable signal degradation due to the generation of intermodulation distortion products (IMD). IMD is the result of the nonlinear behavior of devices, and arises when the original signal mixes with a second signal at a second frequency to generate a third signal at a third frequency [87-88]. Nonlinear device behavior also generates harmonic signals at frequencies which are an integer multiple of the input signal. A summary of the different types of distortion caused by IMD and harmonic signal generation are shown in Figure 8. The net result is that nonlinear distortion takes energy from the desired signal at the frequency of interest, thus reducing the amplitude of this signal, and uses the energy to generate harmonic and IMD signals at frequencies which may interfere with the signal of interest.

The higher RF power-handling capabilities of tunable dielectric varactors relative to semiconductor varactors appears to be primarily due to device configuration differences which enable the RF fields to be spread over larger volumes in tunable dielectric devices. The electrode gap and width in tunable dielectric varactors are typically 5-20 $\mu \mathrm{m}$ and $0.5-1.0 \mathrm{~mm}$, respectively, and the RF and dc voltages are spread across the gap. By contrast, the RF and electric fields in semiconductor varactors are concentrated across the space charge depletion region, which is generally less than $200 \mathrm{~nm}$ wide for varactors with less than $1.0 \mathrm{pF}$ capacitance $[25,89]$. In addition, the low capacitance values required for many microwave



Figure 8.-Intermodulation distortion caused by transmission of signals through nonlinear components. 
applications are achieved by decreasing the anode electrode areas of semiconductor varactors to dimensions as small as $2.5 \times 10^{-7} \mathrm{~cm}^{2}$, thus compressing the RF fields into progressively smaller volumes and decreasing the RF power-handling capability. The trend towards smaller varactor dimensions to achieve lower capacitance contrasts with the need for devices with adequate RF power-handling capabilities to support large bandwidth communication applications.

Higher RF power-handling capabilities in tunable dielectric devices are achieved at a cost, and this cost is the higher dc voltage levels required to tune the devices. It is well known that the RF voltage levels for semiconductor varactors must be substantially lower than the tuning voltages so as to avoid nonlinear behavior [27], and this observation appears to be valid for tunable dielectric varactors as well [90]. A general trend which summarizes the relationship between IMD (as well as other nonlinear signal) levels and the $\mathrm{dc}$ voltage levels required to tune the device is given by:

$$
\mathrm{IMD} \equiv \frac{\mathrm{V}_{\mathrm{RF}}}{\mathrm{V}_{\mathrm{dc}}}
$$

Tunable devices are intrinsically nonlinear and thus susceptible to the generation of IMD and harmonic signals. Applications which require large RF power levels to be transmitted through the tunable sections without signal distortion must be designed so the $\mathrm{dc}$ voltages required for tuning substantially exceed the RF voltage levels transmitted through the device. Although control circuitry which requires hundreds of volts for tuning is less attractive than a circuit which requires tens of volts, it's unlikely that both high RF power handling capability and low tuning voltages can be achieved in a single device. However, it is possible that the RF power handling capability of tunable electric devices can be tailored simply by adjusting the gap size.

The development of a two-tone test protocol to quantitatively establish the level of IMD in tunable dielectric varactors and initial IMD measurements on STO varactors has been reported $[91,92]$. The test procedure consists of inserting the varactor into a resonant microstrip element, which, in turn, is capacitively coupled to the RF input and output lines. The test circuit is shown schematically in Figure 9. 
The RF voltage across the varactor is a function of the RF input voltage, position of the varactor along the resonator, circuit Q, coupling between the input, output, and resonator microstrip lines, and several other parameters. Measurements of the fundamental signal power level $\left(\mathrm{P}_{1, \text { out }}\right)$ and third order IMD product $\left(\mathrm{P}_{\text {3.out }}\right)$ demonstrate that at the highest RF input levels permissible by the test apparatus, the strength of the third order IMD signal was more than $20 \mathrm{~dB}$ below the fundamental signal level when no bias was applied to the varactor, and more than $30 \mathrm{~dB}$ lower than the fundamental signal when a $100 \mathrm{~V}$ bias was applied (Fig. 10). Although more recent data indicate that IMD levels are strongly influenced by gap size and film microstructure, the measurements shown in Figure 10 indicate that the tunable dielectric varactors are capable of providing RF tuning at high RF signal levels while maintaining signal distortion below levels which could impair system performance.

\section{Applications}

Tunable dielectric films provide a means of introducing tuning into microwave and millimeter-wave circuits which cannot be achieved using existing ferrite and semiconductor tuning technologies because of design issues, insufficient power-handling capabilities of the tuning elements, or poor $Q$ values at the operating frequencies. Tunable dielectric varactors and devices will be used in applications with the following requirements: small circuit size and acceptable $Q(\geq 500)$ values at frequencies above $10 \mathrm{GHz}$, fast tuning, and moderate-to-high RF power handling capability. These properties are particularly attractive for large-bandwidth, Ka-band communication systems. Additional advantages are the low dc power levels required to tune the materials and the low fabrication cost, which opens the possibility for low-cost varactors and devices which can be used for applications such as miniaturized tunable local oscillators, electronically steerable phased-array antennas, and adaptive frequency response bandpass and bandreject filters. In this section, we outline the design considerations used for various devices, and review the performance of tunable proof-of-concept devices designed to support large bandwidth applications at Ku-band and higher frequencies. 


\section{Planar capacitor}

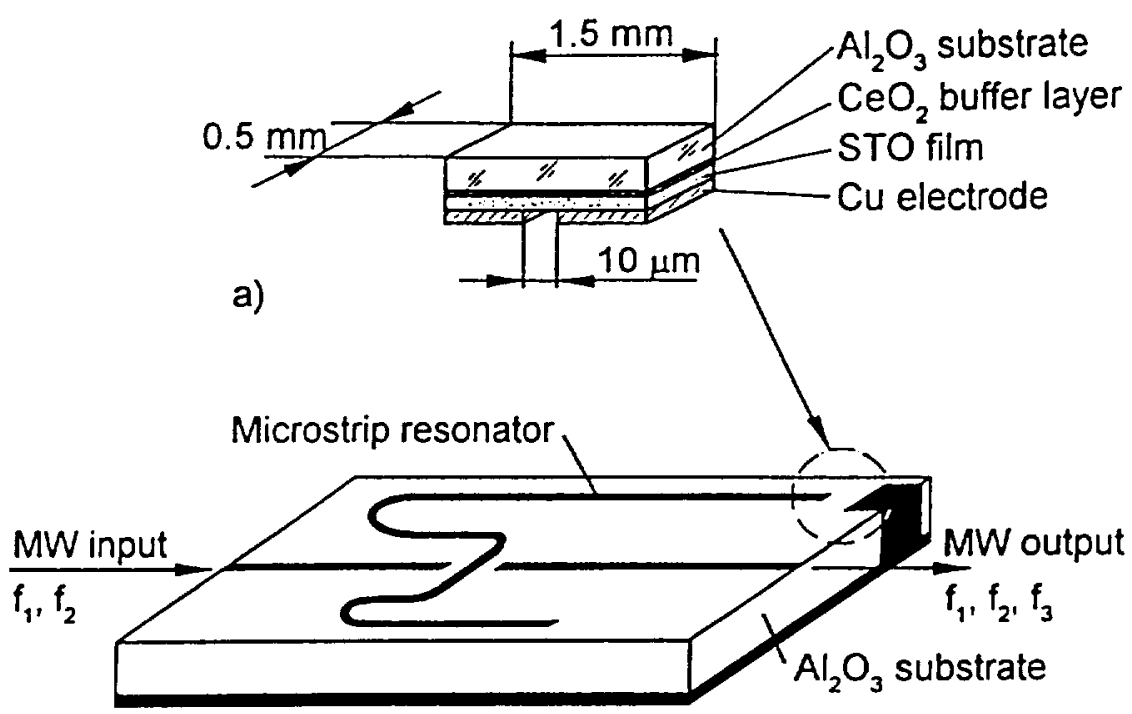

b)

Figure 9.-Test circuit for measuring third order intermodulation distortion in tunable dielectric varactors. (a) Planar capacitor. (b) Microstrip resonator.

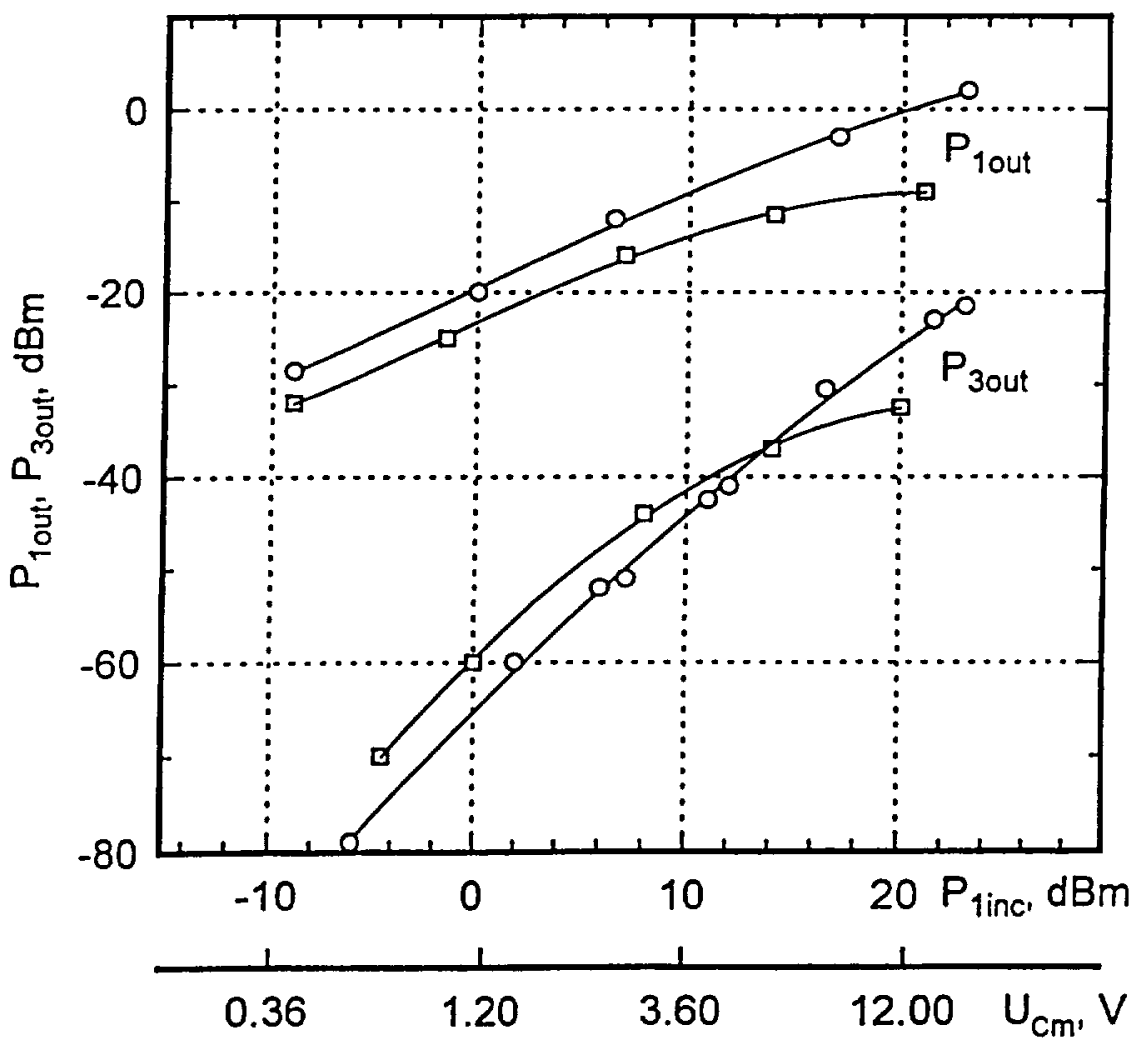

Figure 10.-RF power levels of fundamental and third order intermodulation distortion as a function of input power. The lower abcissa $\left(\mathrm{U}_{\mathrm{cm}}\right)$ shows the RF voltage level across the varactor. Squares denote the RF input and output power levels with no bias applied to the varactor, and circles denote the performance with 100 volts applied to the varactor. 


\section{$\underline{\text { A. Filters }}$}

Bandpass and bandreject filters are used in the receiver front end to ensure that only signals in the desired frequency range enter the receiver. Because the performance of miniaturized microwave and millimeterwave devices is extremely sensitive to minor deviations in parameters such as linewidth and substrate thickness, it is difficult to manufacture filters within the prescribed frequency specifications. Thus, some degree of tuning is generally required. The base station transmit filtering requirements for cellular and PCS applications are currently satisfied using air or dielectric-filled cavity filters. In these filters, frequency tuning is achieved by mechanically screwing a metal or dielectric material into or out of the cavity, which perturbs the electromagnetic fields in the cavity and brings the resonant frequency into the desired range [93]. Although it is fairly simple to tune a single resonator by mechanical means, tuning an entire filter is considerably more difficult because one resonant element will perturb the fields in the other resonant elements. An additional complication is the possibility of frequency drifting caused by detuning of the resonators or filters. The expense and reliability concerns surrounding mechanically tuned filters could be surmounted by using electronically tuned filters. Electronic tuning has the potential to be a much quicker tuning method, and would enable filters and resonators to be adaptively tuned from remote locations. The disadvantage of electronic tuning is that a portion of the electromagnetic field must propagate through the tuning element; because the $Q$ of the tuning element is generally lower than that of the nontunable portion of the resonator, the overall resonator $Q$ is lowered, thus degrading filter performance. Various techniques have been developed to couple the capacitance of the tuning elements to that of cavity and microstrip resonators [94-97].

Planar filters comprised of microstrip, stripline, or finline filters on insulating substrates offer a low-cost means of providing filtering, but are difficult to fabricate to the required frequency and bandwidth specifications. Low-cost, small-size filters are preferably fabricated on polycrystalline, high $\varepsilon_{\mathrm{r}}$ substrates and it is extremely difficult to manufacture filters within precise frequency tolerances because the metallization linewidths are smaller than the linewidths of lower $\varepsilon_{\mathrm{r}}$ substrates, and small deviations in substrate thickness and surface roughness cause unacceptably large deviations in the frequency response. 
In order to make small-size filters commercially viable, a low-cost means of implementing electronic tuning to bring the filters within specifications must be developed. For planar microstrip filters with onehalf wavelength long resonant elements, tuning is accomplished by adding tunable capacitors to one of the open circuited ends of the resonant element, where the amplitude of the RF electric field is at or close to a maximum. The tunable capacitor increases the electrical energy stored in the resonant element, thus effectively lengthening the resonator and decreasing its resonant frequency. Frequency tuning of the resonator is proportional to the capacitance tuning of the varactor, and the frequency tuning range is proportional to the fraction of RF energy stored in the varactor relative to the energy stored in the nontunable portion of the resonator [60]. For applications where only modest tuning is desired, such as those required to bring filters within specifications, small capacitance varactors (typically less than $0.5 \mathrm{pF}$ for applications above $2 \mathrm{GHz}$ ) are required.

A more ambitious use of filter tuning is to adaptively correct for Doppler shifted frequencies in LEO satellite communication systems. Since the satellite is moving relative to the earth station, the received frequencies will be shifted relative to the transmitted frequencies. For example, at Ka-band frequencies, NASA estimates that for space platforms requiring $155 \mathrm{Mbps}$ data rates and $64 \mathrm{MHz}$ bandwidths (e.g. Direct Data Distribution project) Doppler effect induced frequency shifts of $\pm 500 \mathrm{kHz}$ are expected [98]. One option for alleviating this problem is simply to make the bandwidth of the filter sufficiently large that the Doppler shifted signal is transmitted into the receiver. However, this is an inefficient means of utilizing the frequency spectrum, and as the number of satellite systems vying for available spectrum increases, it will become necessary to implement technologies which reduce co-channel interference and make optimal use of the available frequency spectrum. Adaptive tuning is an attractive method to help reach these goals.

A proof-of-concept, tunable two-pole bandpass filter was recently demonstrated at NASA-Lewis $[99,100]$. The microstrip filter was comprised of a YBCO/STO film on LAO substrate, with the YBCO patterned as shown in Figure 11 . At 77K, The filter displayed a $4 \%$ bandwidth, non de-embedded 

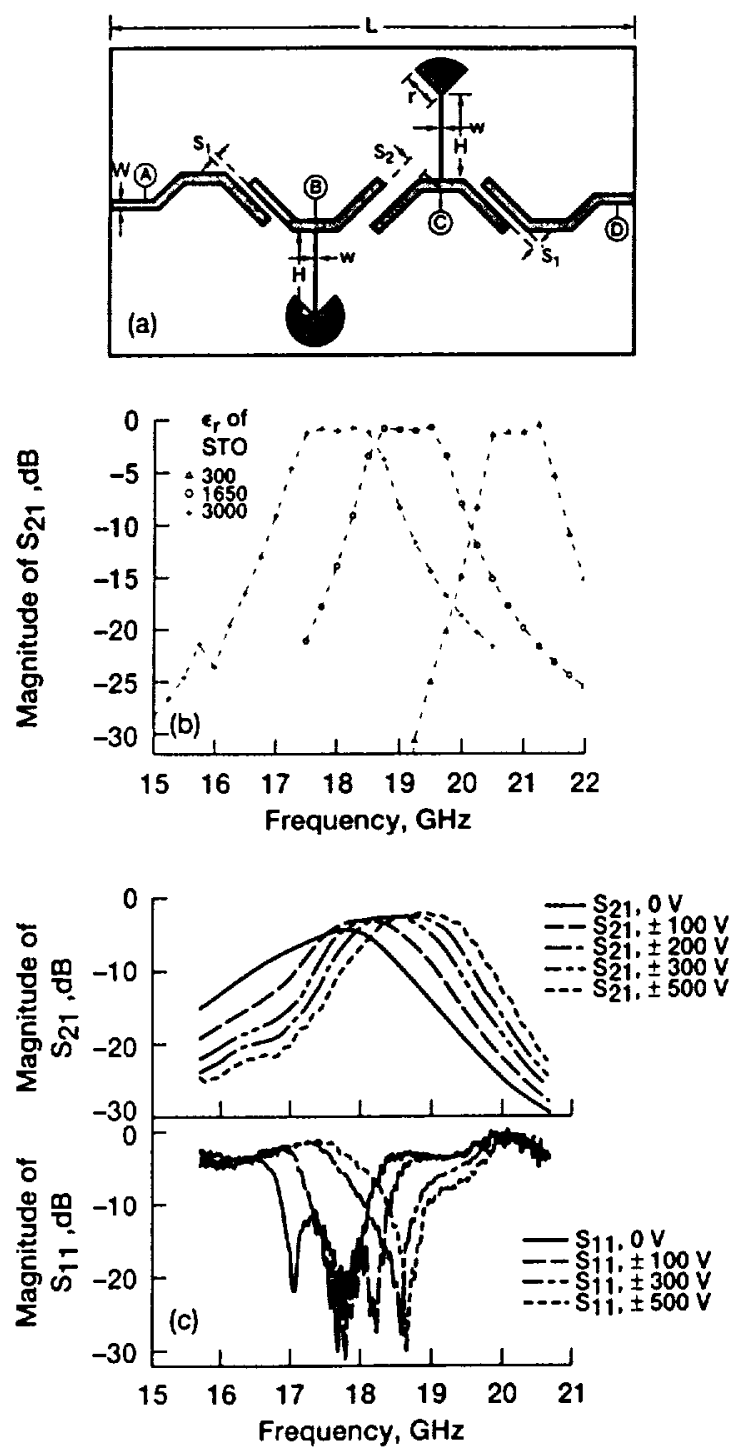

Figure 11.-(a) Schematic of a tunable bandpass filter circuit. The dimensions are $W=86.25 \mu \mathrm{m}, L=6.8 \mathrm{~mm}, S_{1}=100 \mu \mathrm{m}, S_{2}=300 \mu \mathrm{m}, H=1.33 \mu \mathrm{mm}$, and $W=12.5 \mu \mathrm{m}$, and $r=200 \mu \mathrm{m}$. (b) Simulated data showing transmission $\left(S_{21}\right)$ versus frequency for different values of film $\varepsilon_{r}$. (c) Experimental data showing $S_{21}$ and reflection $\left(S_{11}\right)$ versus frequency as a function of dc bias. 
insertion loss of $1.5 \mathrm{~dB}$, and was tunable over a range of approximately $17.5-19 \mathrm{GHz}$. A microstrip bandreject filter (Ku-band) fabricated by the same group displayed high in-band rejection and a tunability range of over $2 \mathrm{GHz}$ [101]. The band reject filter design and performance are shown in Figures 12 and 13. This work demonstrates that the tuning-to-loss ratio of the filter is not simply a function of the tuning and dielectric loss of the tunable dielectric film, but is strongly related to the biasing scheme and resonator design.

A proof-of-concept, adaptively tunable bandreject filter suite which provides in-band rejection from 8.5- $10.5 \mathrm{GHz}$, was demonstrated by SCT, Inc. The filter suite is comprised of four separate filters, with each filter capable of at least $40 \mathrm{~dB}$ adaptable rejection within a $500 \mathrm{MHz}$ band. Each filter contains three


(a)



(b)

Figure 12.-Microstripline side-coupled ring resonator. $W=406 \mu \mathrm{m}$ for the $25 \Omega$ ring and $89 \mu \mathrm{m}$ for the $50 \Omega$ ring. $w=89 \mu \mathrm{m}$, $\mathrm{g}=25 \mu \mathrm{m}$, and $\mathrm{r}=1694 \mu \mathrm{m}$. 


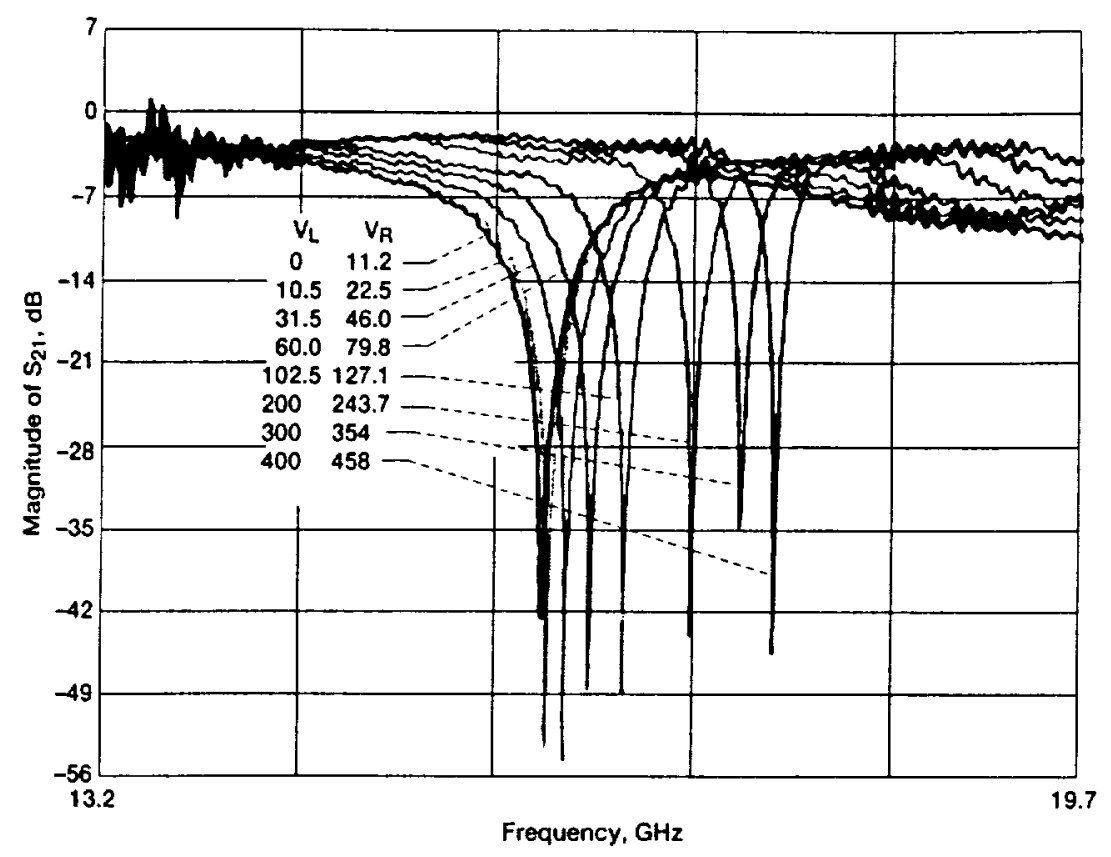

Figure 13.- Effect of dc bias on the $3 \lambda$ resonant frequency $\left(f_{0}\right)$ and sharpness of resonance $\mathrm{df}_{\mathrm{n}}{ }^{-1}$ for a Au/STO/LAO ring resonator at $77 \mathrm{~K}$. The ring is biased at $V_{R}$ and line at $V_{L}$, where $V_{R}>V_{L}$.

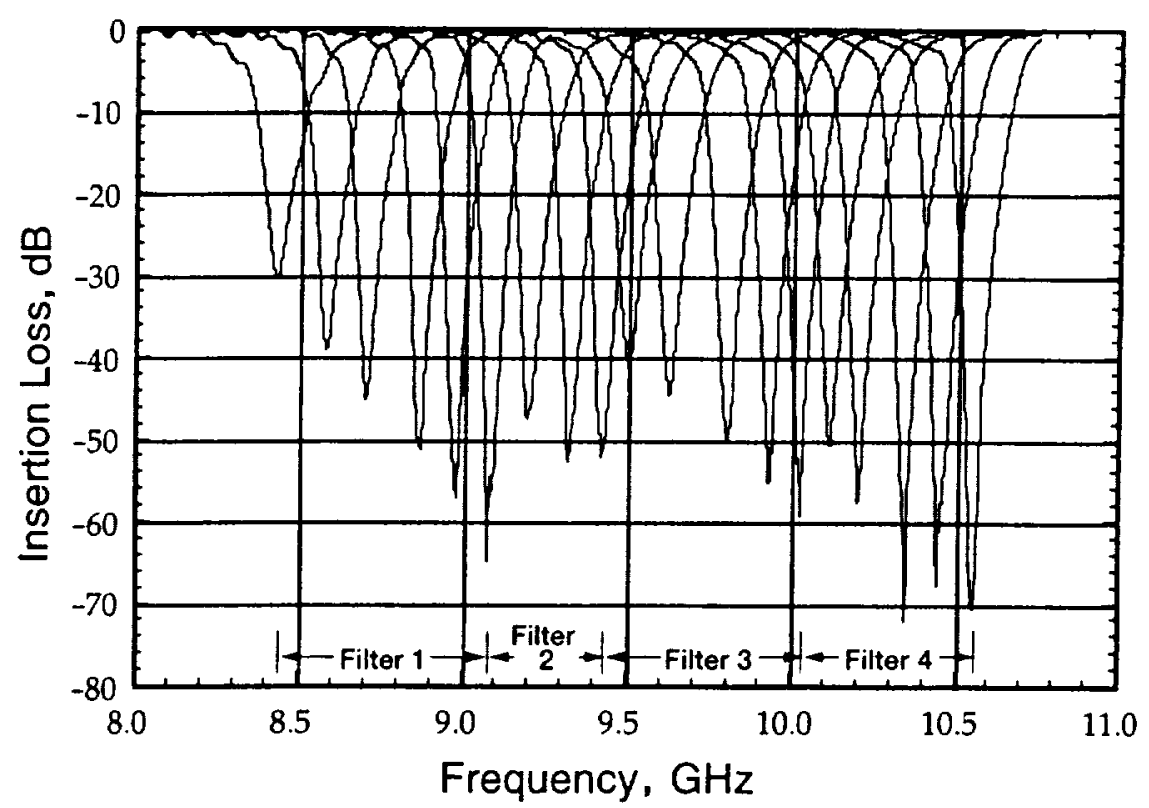

Figure 14.-Performance of tunable bandreject filter used in $8.5-10.5 \mathrm{GHz}$ suite. Each filter contains three tunable resonators, and the resonators are overlapped to increase the signal rejection.

tunable resonators, and the bias voltages across each resonator were adjusted so as to overlap the resonances and thus increase the rejection. Tuning speed measurements showed that the time required for the resonators to shift from one frequency to another was less than $10 \mathrm{~ns}$. The performance of the fourfilter suite is shown in Figure 14. 


\section{B. Phase Shifters}

Unquestionably, the use of tunable dielectric materials in the beam steering circuitry of phased array antennas is the most ambitious and potentially far-reaching as well as lucrative application of tunable dielectric materials. The advantages and attributes of beam-steerable phased-array antennas for Ka-band wireless systems are outlined in Section II.A.

Although it is beyond the scope of this chapter to provide a detailed description of phased array antenna and phase shifter design, some background is needed to understand the rationale for proposing tunable dielectric materials for these devices. More detailed information regarding phased array antenna and phase shifter design is available $[19,27,29,102-104]$. The key elements which enable beam steering in adaptive antennas are the phase shifters. These antennas are generally comprised of two-dimensional arrays of radiating elements spaced $\lambda_{0} / 2$ apart, where $\lambda_{0}$ is the free-space wavelength of the signal. The angle at which the antenna beam is radiated or received is established by the angle at which constructive interference between radiating elements occurs. This angle is controlled by varying the electrical phase between adjacent radiating elements. The phase shift between adjacent radiating elements $(\phi)$ required to produce a scan angle $\left(\theta_{0}\right)$ is given by:

$$
\phi=\frac{2 \pi}{\lambda_{0}} s\left(\sin \theta_{0}\right)
$$

where $s$ is the distance between radiating elements. The scan angle, $\theta_{0}$, is assumed to be relative to broadside (i.e. normal to the plane of radiating elements). Equation 4 illustrates that electronically altering the phase difference between radiating elements enables the direction of the antenna beam to be steered. The key characteristics sought in phase shifters for phased array antennas are:

- Low insertion loss. Less than $3 \mathrm{~dB}$ insertion loss for 360 degrees of phase shift is generally tolerated, and lower insertion loss values are highly desirable.

- Time delay operation. Ideally, phase shift is independent of frequency over a wide bandwidth. This criteria is met for digital switched line phase shifters, where an ideal switch is used to route 
the signal along one of two pathways. Phase shift is accomplished because the electrical lengths of the two pathways are different. At Ku-band and lower frequencies, PIN diodes and field effect transistors (FET's) perform well as electrical switches, but their performance degrades at higher frequencies due to increased insertion loss. Several ferrite phase shifters also provide digital operation, most notably the twin-toroid and dual-mode types. The Reggia Spencer ferrite phase shifter is a true-time delay, analog phase shifter.

- Driver and drive power. The complexity and power requirements of the circuitry used to control the phase will have a large impact on the applicability of the phase shifter technology for a given application. For example, dual mode ferrite phase shifters can easily meet the performance requirements for Ka-band phase shifters, but the cost and tuning power requirements make ferrite technologies an unlikely choice for low-cost, low-power wireless applications.

- RF power handling capability. The RF voltage amplitudes across the control elements (e.g. PIN diode, FET, ferrite element, or varactor (e.g. semiconductor or tunable dielectric) must be sufficiently low that they do not modulate the control elements. Power-handling capability is generally not an issue for bulk ferrite control elements or PIN semiconductor diodes, but is the major limitation which prevents widespread use of semiconductor varactors for transmit applications. The fact that tunable dielectric varactors appear to have much higher RF power handling capabilities than semiconductor varactors makes them attractive for applications such as short-range radar, where low cost, low weight, fast switching speeds, and analog beam steering are essential.

Although Ka-band phase shifters with acceptable performance levels can be fabricated using ferrite or digital semiconductor devices, they are impractical for all commercial and most non-commercial applications because of their high cost [19]. Tunable dielectric phase shifters offer the potential for lowcost, high-performance phase shifters at Ka-band frequencies. They do not suffer from the same loss mechanisms which degrade the performance of semiconductor varactors at microwave frequencies (series electrode losses), and the ease with which the films can be prepared enables large arrays of phase shifters 
to be fabricated at low cost. Prior work has established that the dielectric constants of highly epitaxial BSTO and STO thin films can be easily tuned using dc voltages, and the power dissipated by the tuning circuitry is negligible, thus making tunable dielectrics an attractive technology for applications where power is limited, such as deep-space missions or portable consumer devices. A schematic of a prototype phase shifter demonstrating over 360 degrees of phase shift at Ku-band frequencies is shown in Figure 15 , and the experimentally observed phase shift at cryogenic [105], and room temperatures [106] are shown in Figures 16 and 17, respectively. Improved film processing techniques and tuning configurations are currently being explored to reduce the insertion losses in Ka-band cryogenic and ambient-temperature 360 degree phase shifters. Key issues to resolve are the interplay between film $\varepsilon_{\mathrm{r}}$ and metallization losses, and evaluation of which device configurations (i.e. microstrip, suspended stripline, or finline) provide optimal performance at Ka-band. In addition to device design, there are basic materials barriers which must be overcome before this technology will be used outside the laboratory. Capacitive hysteresis is extremely detrimental to phase shifters because phased array antennas require precise correlation between tuning voltage and phase shift so as to avoid beam degradation.

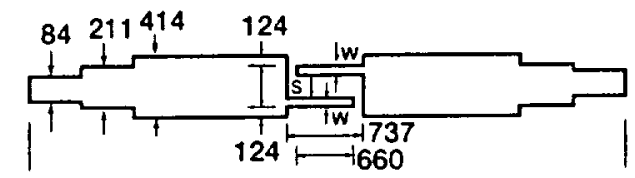

(a)

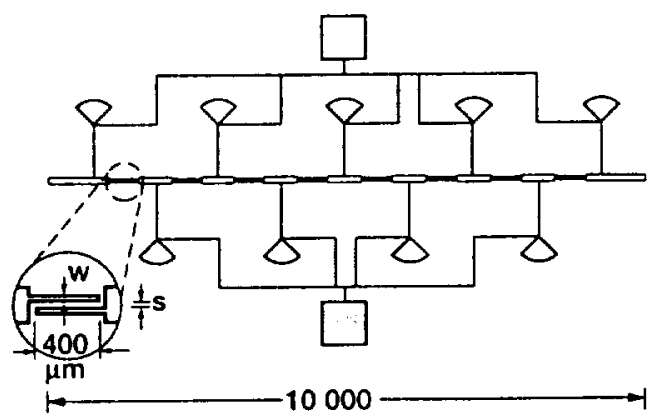

(b)

Figure 15.-(a) Single-element phase shifter (with input/output 50 to $25 \Omega$ transformers) $S=12.7 \mu \mathrm{m}, W=76.2 \mu \mathrm{m}$. (b) Schematic of eight-element, $50 \Omega$ coplanar microstrip phase shifter. $S=7.5 \mu \mathrm{m}$ and $W=25 \mu \mathrm{m}$. 

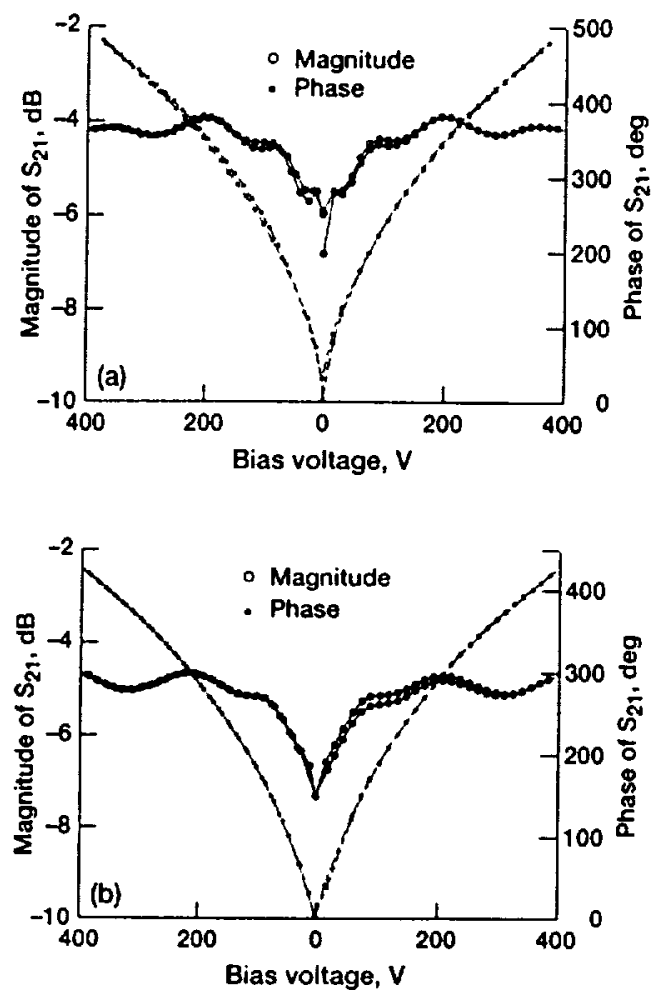

Figure 16.-Transmission magnitude and phase values for a $50 \Omega$, eight-element coplanar microstrip phase shifter using YBCO $(0.35 \mu \mathrm{m} /$ STO $(1.0 \mu \mathrm{m}) / \mathrm{LAO}(254 \mu \mathrm{m})$. Data were taken at $\mathrm{T}=40 \mathrm{~K}$ and $16 \mathrm{GHz}$. (b) Same phase shifter as in (a), but data taken at $\mathrm{T}=77 \mathrm{~K}$ and $16 \mathrm{GHz}$.

Transmission-type tunable dielectric phase shifters have been demonstrated at the Electrotechnical Institute [107], and a schematic of a $1.9 \mathrm{GHz}$ phase shifter is shown in Figure 18. For measurements at $77 \mathrm{~K}$, thin film STO varactors were soldered into the shunt arms, and 120 degrees of phase shift with less than $1.0 \mathrm{~dB}$ insertion loss was obtained by varying the capacitance of the varactors from $2.2-1.1 \mathrm{pF}$. At room temperature, varactors comprised of thick film BSTO $(3 \mu \mathrm{m})$ on $\mathrm{MgO}$ substrates were inserted into the circuit, and a phase shift of 110 degrees was obtained with less than $1.5 \mathrm{~dB}$ insertion loss over the entire tuning range. However, the dc voltages required to tune the ambient temperature device were higher than the voltages required at $77 \mathrm{~K}$; up to $400 \mathrm{~V}$ were used to tune the BSTO varactors, whereas the maximum dc voltage for the STO varactors was $90 \mathrm{~V}$. The phase shifter utilizes a hybrid-coupled, transmission-type design; the signal is split between two arms, with the varactors located such that the transmitted signals constructively interfere at the output port, and the reflected signals destructively 

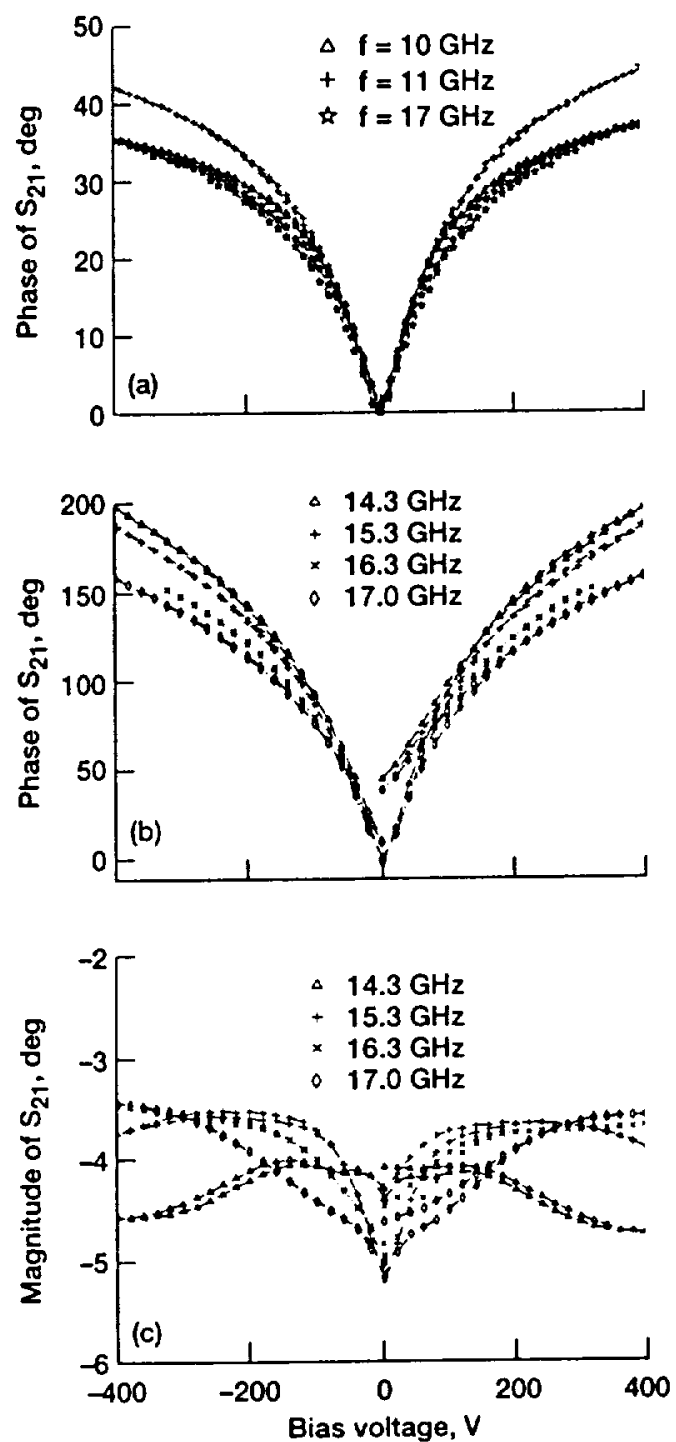

Figure 17.-(a) Phase shift of $S_{21}$ versus dc bias voltage for a $25 \Omega$ single element Au $(2.5 \mu \mathrm{m}) / \mathrm{Ba}_{0} .6 \mathrm{Sro}_{.4} \mathrm{TiO}_{3}(300 \mathrm{~nm}) / \mathrm{LOO}(254 \mu \mathrm{m})$ phase shifter. Data were taken at $300 \mathrm{~K}$. (b) Phase shift of $\mathrm{S}_{21}$ for a $50 \Omega$ eight-element $\mathrm{Au}(2.5 \mu \mathrm{m}) / \mathrm{Ba} 0.5 \mathrm{Sr}_{0.5} \mathrm{TiO}_{3}$ $(300 \mathrm{~nm}) / \mathrm{LAO}(254 \mu \mathrm{m})$ phase shifter at $302 \mathrm{~K}$. (c) Magnitude of $S_{21}$ for phase shifter in (b) at $302 \mathrm{~K}$. 


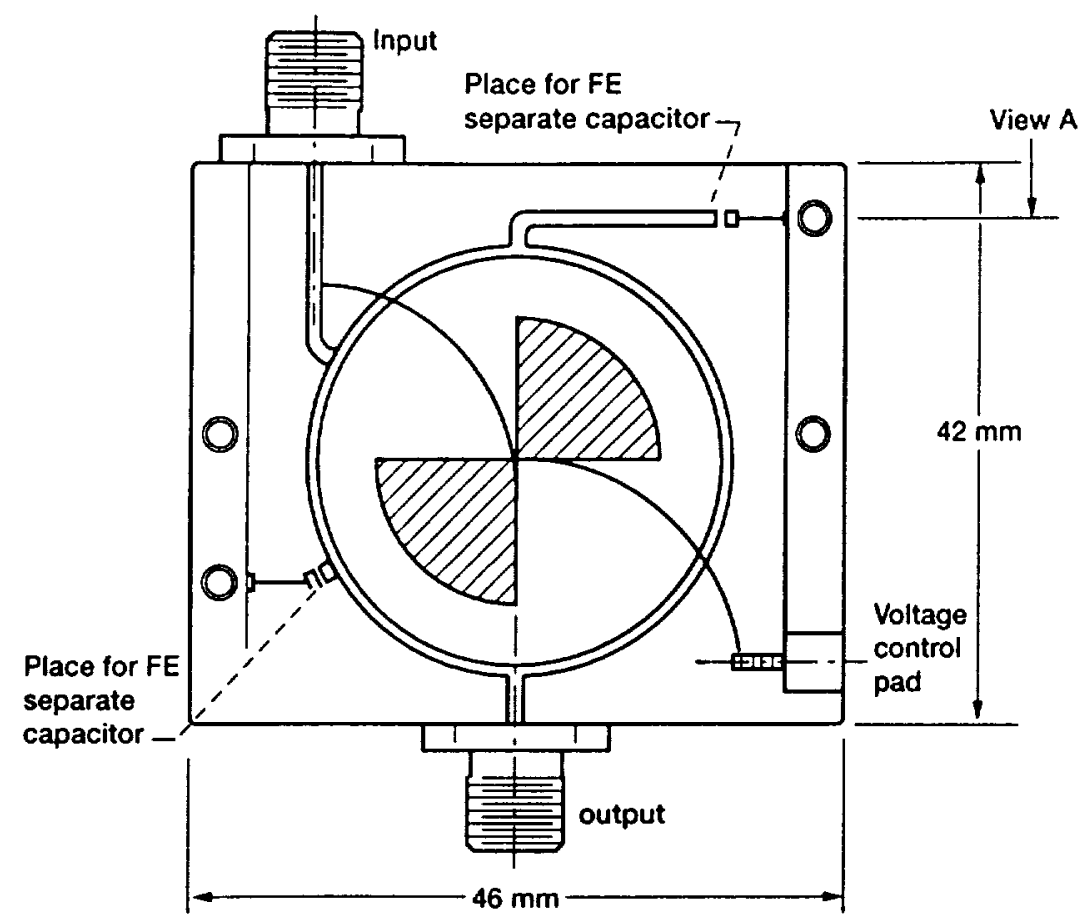

Figure 18.-Schematic of transmission-mode, 1.9 GHz phase shifter. Tuning is accomplished by varying the capacitance of tunable dielectric varactors located in the shunt arms.

interfere at the input port. A large advantage of this type of circuit is its effectiveness in minimizing reflection losses. Since losses due to signal reflection are a major source of microwave loss in most planar circuits (due to impedance mismatch resulting from the varying $\varepsilon_{\mathrm{r}}$ of the tunable dielectric film), the fact that the shunt-loaded transmission structure minimizes this problem makes it a very promising for a wide variety of phased array antenna applications. To achieve 360 degrees of phase shift, several sections such as shown in figure 18 would need to be cascaded. In practice, phased array antennas with $10-20 \%$ bandwidths are generally designed so that each section provides less than 30 degrees of phase shift [27], thus the results shown above demonstrate the potential for developing low-cost phase shifters using tunable dielectric materials.

We believe that low-cost, electronically controlled phased array are more likely to be realized with optimized tunable dielectric devices than existing semiconductor technology. To obtain the necessary signal control across the breadth of the antenna will require delays of considerably greater than 
360 degrees. As already discussed in this chapter, tunable dielectric phase shifters capable of phase shifts above 360 degrees have already been demonstrated, thus rendering support to the concept of phased arrays implementation based solely on tunable dielectric technology. However, it is also possible that a hybrid concept, comprised of some combination of semiconductor and tunable dielectric devices, could result in low-cost phased array antennas. How to integrate these two technologies for use in control devices in a cost-effective manner is a question requires require further consideration.

\section{Conclusions}

There are a number of microwave applications where tunable dielectric devices could play a key role in improving system performance, or perhaps provide the key technology which enables a system to be deployed. We anticipate that the most promising applications are in broadband wireless communications systems where the user-to-satellite and user-to-base station links must be at Ka-band so as to support high data rate transmission applications. Traditional tuning methods have not demonstrated that they are capable of meeting the performance and cost requirements for these applications, whereas prototype tunable dielectric devices have shown considerable promise. Although, there are still a number of materials and device issues which must be resolved before serious commercialization of tunable dielectric devices will take place, the foreseen impact of this technology is extraordinary.

\section{REFERENCES}

1. Shafi, M., Hashimoto, A., Umehira, M., Ogose, S., and Murase, T. (1997). Wireless Communications in the Twenty-First Century: A Perspective. Proc. IEEE 85, 1622-1638.

2. K. Tanzillo, Communication News, 12 (Sept. 1996).

3. K. Gardner, Newaves, 42 (May, 1996).

4. R. Westerveld and R. Prasad, IEEE Comm. Mag., 70 (Oct., 1994).

5. Pelton, J. (April 1998). Telecommunications for the $21^{\text {st }}$ Century. Scientific American, 80-85.

6. Http://www.globalstar.com

7. Microwave Jour. 41, 132 (March, 1998).

8. Black, U. (1997). "Emerging Communication Technologies" p. 6. Prentice Hall, London. 
9. Ivancic, W. (1998). Progress Toward Standards for the Seamless Interoperability of Broadband Satellite Communication Networks. NASA TM-206617.

10. Sweeney, D. (May 1997). Celestial Pipelines for Multimedia Satellite Communications, p.26-31.

11. Http://www.teledesic.com.

12. Freeman, R.L. (1997). "Radio System Design for Telecommunications" p. 491.John Wiley and Sons, New York.

13. Rogers, D., Ippolito, L., and Davarian, F. (1997). System Requirements for Ka-Band Earth-Satellite Propagation Data. Proc. IEEE 85, 810-820.

14. Garg, V. and Wilkes, J. (1996). "Wireless and Personal Communications Systems" p.9. Prentice Hall, London.

15. Pierce, J. and Noll, A. (1990). "Signals: The Science of Telecommunications" p.51. Scientific American Library, New York.

16. Bundy, S. (March 1998). Noise Figure, Antenna Temperature and Sensitivity Level for Wireless Communication Receivers. Microwave Joumal 41, 108-116.

17. Javadi, H. (1996). Jet Propulsion Laboratory/NASA Lewis Research Center Space Qualified Hybrid High Temperature Superconducting/Semiconducting 7.4 GHz Low-Noise Downconverter for NRL HTSSE-II Program. IEEE Trans. Microwave Theory and Tech. 44, 1279-1288.

18. Godara, L. (1997). Applications of Antenna Arrays to Mobile Communications, Part I: Performance Improvement, Feasibility, and Systems Considerations. Proc. IEEE 85, 1031-1060.

19. Brookner, E. (1997). Major Advances in Phased Arrays: Part I. Microwave Journal 40, 288-294.

20. Gikow, E. (1971). Voltage Variable Ferroelectric Capacitor. U.S. Patent No. 3,569,975.

21. Private discussion with Z. Zhang (SCT, Inc.), 1997.

22. Houlding, N. (July 1966). Characterization and Measurement of Varactors. Microwave Joumal, 53-58.

23. Tyagi, M.S. (1991). "Introduction to Semiconductor Materials and Devices," p.301. John Wiley and Sons, New York.

24. K.E. Mortensen, "Variable Capacitance Diodes," (Artech, Dedham, 1974). P. 46.

25. Maas, S. (1997). "Nonlinear Microwave Circuits," p. 55. IEEE Press, New York.

26. Louhi, J. and Raisanen, A. (1996). Dynamic Shape of the Depletion Layer of a Submillimeter-Wave Schottky Varactor. IEEE Trans. Microwave Theory Tech. 44, 2159-2164.

27. White, J. (1982). “Microwave Semiconductor Engineering." P. 47. Van Nostrand, New York.

28. Caverly, R. (December 1997). Distortion in RF and Microwave Control Devices. Microwave Journal, 74-82. 
29. T.C. Cheston and J. Frank, in "Radar Handbook," edited by M.I. Skolnik (McGraw-Hill, New York, 1990). P. 7.63 .

30. Microwaves and RF, (August, 1996).

31. D.E. Oates, A. Pique, K.S. Harshavardhan, J. Moses, J.F. Yang, and G.F. Dionne, IEEE Trans. Appl. Supercond. 7, 2338 (1997).

32. Harsany, S. (1997). "Principles of Microwave Technology." P. 110. Prentice-Hall, Columbus.

33. Davis, L. and Rubin, L. (1953). Some Dielectric Properties of Barium-Strontium Titanate Ceramics at 3000 Megacycles. J. Appl. Phys. 24, 1194-1197.

34. Gerson, K., Peterson, J. and Rote, D. (1963). Dielectric Constant of Lead Titanate Zirconate Ceramics at High Frequency. J. Appl. Phys. 34, 3242-3245.

35. Rupprecht, G., Bell, R., and Silverman, B. (1961). Nonlinearity and Microwave Losses in Cubic StrontiumTitanate. Phys. Rev. 123, 97-98.

36. Rupprecht, G. and Bell, R. (1962). Microwave Losses in Strontium Titanate above the Phase Transition. Phys. Rev. 125, 1915-1920.

37. Silverman, B. (1962). Microwave Absorption in Cubic Strontium Titanate. Phys. Rev. 125, 1921-1929.

38. Furukawa, O., Yoshida, S., Imai, M., and Harata, M. (1988). High Dielectric Constant Ceramic Material and Method of Manufacturing the Same. U.S. Patent No. 4747732.

39. Shrout, T. and Dougherty, J. (1990). "Ceramic Dielectrics: Composition, Processing and Properties" (H.C. Ling and M.F. Yan, Eds.) p.3. American Ceramic Soc., Westerville.

40. Cross, L. (1987). Relaxor Ferroelectrics. Ferroelectrics 76, 241-267.

41. Zuccaro, C., Winter, M., Klein, N., and Urban, K. (1997). Microwave Absorption in Single Crystals of Lanthanum Aluminate. J. Appl. Phys. 82, 5695-5704.

42. V.L. Gurevich and A.K. Tagantsev, Advances in Physics 40. 719 (1991).

43. S. Kazaoui, J. Ravez, C. Elissalde, and M. Maglione, Ferroelectrics 135, 85 (1992).

44. A.K. Tagantsev, J. Petzelt, and N. Setter, Sol. St. Comm. 87, 1117 (1993).

45. J. Petzelt and N. Setter, Ferroelectrics 150, 89 (1993).

46. R. Zurmuhlen, E. Colla, D.C. Dube, J. Petzelt, I. Reaney, A. Bell, and N. Setter, J. Appl. Phys. 76, 5864 (1994).

47. Scott, J., Galt, D., Price, J., Beall, A., Ono, R., Paz De Araujo, C., and McMillan, L. (1995). A Model of Voltage-Dependent Dielectric Losses for Ferroelectric MMIC Devices. Integrated Ferroelectrics 6, 189-203.

48. Larsen, P. ,Dormans, G., Taylor, D., and Veldhoven, P. (1994). Ferroelectric Properties and Fatigue of $\mathrm{PbZr}_{0.51} \mathrm{Ti}_{0.49} \mathrm{O}_{3}$ Thin Films of Varying Thickness: Blocking Layer Model. J. Appl. Phys. 76, 2405-2413. 
49. Sengupta, L., Ngo, E., Stowell, S., O'Day, M., and Lancto, R. (1994). Ceramic Ferroelectric Composite Materila-BSTO-MGO. U.S. Patent No. 5307033.

50. L.C. Sengupta, E. Ngo, and J. Synowczynski, Integrated Ferroelectrics 15, 181 (1996).

51. Private communications with F.S. Barnes (1997). Univ. of Colorado, Boulder.

52. Denlinger, E. (1980). Losses of Microstrip Lines. IEEE Trans. Microwave Theory Tech. 28, 513-522.

53. Varadan, V., Ghodgaokar, D., Vardan, V., Kelly, J., and Glikerdas, P. (January 1992). Ceramic Phase Shifters for Electronically Steerable Antenna Systems. Microwave Journal, 116-123.

54. Koscica. T., Babbitt, R., and Drach, W. (1994). Planar Digital Ferroelectric Phase Shifter. U.S. Patent No. 5307033.

55. Vendik, O., Mironenko, I., and Ter-Martirosyan, L. (1994). Superconductors Spur Applications of Ferroelectric Films. Microwaves and $R F$ 33, 67-70.

56. Mironenko, I. (1976). Principles of Applications and Properties of Ferroelectric Films at Microwave Frequencies. Ferroelectrics 13, 421-422.

57. Vendik, O., Mironenko, I., and Ter-Martirosyan, L. (1972). Superconductors J. de Phys. 33, C2/277 (1972).

58. Galt, D., Price, J., Beall, A., and Ono, R. (1993). Characterization of a Tunable Thin Film Microwave $\mathrm{YBa}_{2} \mathrm{Cu}_{3} \mathrm{O}_{7-\mathrm{x}} / \mathrm{SrTiO}_{3}$ coplanar Capacitor. Appl. Phys. Lett. 63, 3078-3080.

59. D. Galt, J.C. Price, J.A. Beall, and T.E. Harvey, IEE Trans. Appl. Supercond. 5, 2575 (1995)

60. Kozyrev, A., Keis, V., Koepff, G., Yandrofski, R., Soldatenkov, O., Dudin, K., and Dovgan, D. (1995). Procedure of Microwave Investigations of Ferroelectric Films and Tunable Microwave Devices Based on Ferroelectric Films. Microelectronic Eng. 29, 257-260.

61. Findikoglu, A., Doughty, C., Anlage, S., Li, Q., Xi, X., and Venkatesan, T. (1993). Effect of de Electric Filed on the Effective Microwave Surface Impedance of $\mathrm{YBa}_{2} \mathrm{Cu}_{3} \mathrm{O}_{7} / \mathrm{SrTiO}_{3} / \mathrm{YBa}_{2} \mathrm{Cu}_{3} \mathrm{O}_{7}$ Trilayers. Appl. Phys. Lett. 63, 3215-3217.

62. Miranda, F., Mueller, C., Cubbage, C., Bhasin, K., Singh, R., and Harkness, S. (1995). HTS/Ferroelectric Thin Films for Tunable Microwave Components. IEEE Trans. Appl. Supercond. 5, 3191-3194.

63. Miranda, F., Mueller, C., Koepf, G., and Yandrofski, R. (1995). Electrical Response of Ferroelectric/Superconducting/Dielectric $\mathrm{Ba}_{\mathrm{x}} \mathrm{Sr}_{1-\mathrm{x}} \mathrm{TiO}_{3} / \mathrm{YBa}_{2} \mathrm{Cu}_{3} \mathrm{O}_{7-\mathrm{d}} / \mathrm{LaAlO}_{3}$ Thin-Film Multilayer Structures. Supercond. Sci. Technol. 8, 755-763.

64. Miranda, F., Mueller, C., Treece, R., Rivkin,T., Thompson, J., Moutinho, H., Dalberth, M. and Rogers, C. (1996). Effect of $\mathrm{SrTiO}_{3}$ Deposition Temperature on the Dielectric properties of $\mathrm{SrTiO}_{3} / \mathrm{YBa}_{2} \mathrm{Cu}_{3} \mathrm{O}_{7 . \mathrm{d}^{\prime}}$ $\mathrm{LaAlO}_{3}$ Structures. Integrated Ferroelectrics 14, 173-180. 
65. Mueller, C., Treece, R., Rivkin, T., Miranda, F., Moutinho, H., Swartzlander-Franz, A., Dalberth, M., and Rogers, C. (1997). Tunable SrTiO3 Varactors using Parallel Plate and Interdigital Structures. IEEE Trans. Appl. Supercond. 7, 3512 (1997).

66. Carroll, K., Pond, J., Chrisey, D., Horwitz, J., Leuchtner, R., and Grabowski, K. (1993). Microwave Measurement of the Dielectric Constant of $\mathrm{Sr}_{0.5} \mathrm{Ba}_{0.5} \mathrm{TiO}_{3}$ Ferroelectric Thin Films. Appl. Phys. Lett. 62 , 1845-1847.

67. Carter, A., Horwitz, J., Chrisey, D., Pond, J., Kirchoefer, S., and Chang, W. (1997). Pulsed Laser Deposition of Ferroelectric Thin Films for Room Temperature Active Microwave Electronics. Integrated Ferroelectrics 17, 273-286.

68. Williamson, W., Chen, H., Cross, L., and Gilbert, B. (1997). High Frequency Dielectric Properties of PLZT Thin Films. Integrated Ferroelectrics 17, 197-204.

69. Chivukula, V., Ilowski, J., Emesh, I., McDonald, D., Leung, P., and Sayer, M. (1995). Dielectric propertied of Ferroelectric Thin Films in the Frequency range of $\mathrm{mHz}-\mathrm{GHz}$. Integrated Ferroelectrics 10, 247-255.

70. D.C. DeGroot, J.A. Beall, R.B. Marks, and D.A. Rudman, IEEE Trans. Appl. Supercond. 5, 2272 (1995).

71. Findikoglu, A., Jia, Q., Campbell, I., Wu, X., Reagor, D., Mombourquette, C., and McMurry, D. (1995). Electrically Tunable Coplanar Transmission Line Resonators using $\mathrm{YBa}_{2} \mathrm{Cu}_{3} \mathrm{O}_{7-\mathrm{x}} / \mathrm{SrTiO}_{3}$ bilayers. Appl. Phys. Lett. 66, 3675-3677.

72. Treece, R., Thompson, J., Mueller, C., Rivkin, T., and Cromar, M. (1997). Optimization of $\mathrm{SrTiO}_{3}$ for Applications in Tunable Resonant Circuits. IEEE Trans. Appl. Supercond 7, 23632366.

73. Gevorgian, S., Martinsson, T., Linner, P., and Kolberg, E. (1996). CAD Models for Multilayered Substrate Interdigital Capacitors. IEEE Trans. Microwave Theory Tech. 44, 896-904.

74. Wu, H., Zhang, Z., Barnes, F., Jackson, C., Kain, A., and Cuchiaro, J. (1994). Voltage Tunable Capacitors Using High Temperature Superconductors and Ferroelectrics. IEEE Trans. Appl. Supercond. 4, 156-160.

75. Yamamichi, S., Yabuta, H., Toshiyuki, S., and Miyasaka, Y. (1994). (Ba+Sr)/Ti Ratio Dependence of the Dielectric Properties for $\left(\mathrm{Ba}_{0.5} \mathrm{Sr}_{0.5}\right) \mathrm{TiO}_{3}$ Thin Films Prepared by Ion Beam Sputtering. Appl. Phys. Lett. 64, 1644-1646.

76. Neville, R., Hoeneisen, B., and Mead, C. (1972). Permittivity of Strontium Titanate. J. Appl. Phys. 43, 2124-2131.

77. SCT Internal Report, (1995), unpublished.

78. Knauss, L., Pond, J., Horwitz, J., Chrisey, D., Mueller, C., and Treece, R. (1996). The Effect of Annealing on the Structure and Dielectric Properties of $\mathrm{Ba}_{x} \mathrm{Sr}_{1-\mathrm{x}} \mathrm{TiO}_{3}$ Ferroelectric Thin Films. Appl. Phys. Lett. 69, 25-27. 
94. Khanna, A., (1990) in “Dielectric Resonators" (D. Kajfez and P. Guillon, Ed.), p. 510. Vector Fields Press, Oxford, Mississippi.

95. Reynolds, A. (1974). Microwave Cavity Tuning Loop Including a Varactor. United States Patent No. $3,789,322$.

96. Mettoudi, I. (1990). Oscillator Having a Dielectric Resonator, and Electronic Frequency Tuning Using a Varactor, in Particular in the $22 \mathrm{GHz}$ Range. United States Patent No. 4,926,142.

97. Cohen, L., (1991). Millimeter Wave Oscillator With Flicker (1/F) Noise Suppression. United States Patent No. $5,019,791$.

98. "Direct Data Distribution from Low Earth Orbit," J. M. Budinger, et al., NASA TM-107438 (1997).

99. Subramanyam, G. Van Keuls, F., and Miranda, F. (1998). A K-Band Tunable Microstrip Bandpass Filter using a Thin Film Conductor/Ferroelectric/Dielectric Multilayer Configuration. IEEE Microwave and Guided Wave Lett. 8, 78-80.

100. Subramanyam, G., Van Keuls, F., and Miranda, F. (1998). A Novel K-Band Tunable Microstrip Bandpass Filter using a Thin Film HTS/Ferroelectric/Dielectric Multilayer Configuration. IEEE MTT-S Digest, $1011-1014$.

101. Van Keuls, F., Romanofsky, R., Bohman, D., and Miranda, F. (1998). Accepted for publication in Integrated Ferroelectrics.

102. Koul, S., and Bhat, B. (1991). "Microwave and Millimeter Wave Phase Shifters, Volume 1." Artech House, Boston.

103. Koul, S., and Bhat, B. (1991). "Microwave and Millimeter Wave Phase Shifters, Volume 2." Artech House, Boston.

104. Lynn, P. (1987). P. 65. "Radar Systems." Van Nostrand Press, New York.

105. Van Keuls, F., Romanofsky, R., and Miranda, F. (1998). Accepted for publication in Integrated Ferroelectrics.

106. Van Keuls, F. et al. (1998). A Ku-band Gold/Ba $\mathrm{Sr}_{1-\mathrm{x}} \mathrm{TiO}_{3} / \mathrm{LaAlO}_{3}$ Conductor/Thin Film Ferroelectric Microstripline Phase Shifter for Room Temperature Communications Applications. Submitted to Microwave Optical Technology Letters.

107. Kozyrev, A., Osadchii, V., Soldatenkov, O., and Ivanov, A., Eletrotechnical Institute (St. Petersburg, Russia) (1997) Unpublished data. 
79. Al-Shareef, H., Dimos, D., Raymond, M., Schwartz, R., and Mueller, C. (1997). Tunability and Calculation of the Dielectric Constant of Capacitor Structures with Interdigital Electrodes. J. Electroceramics 1, 145-153.

80. Raymond, M., Al-Shareef, H., Dimos, D., Missert, N., Mueller, C., and Galt, D. (1997). Sputter Deposition of $\mathrm{SrTiO}_{3}$ Films for Voltage Tunable Capacitors. Integrated Ferroelectrics 17, 247-256.

81. Lines, M., and Glass, M. (1977). "Principles and Applications of Ferroelectric and Related Materials." P. 71. Clarendon Press-Oxford.

82. Burfoot, J., and Taylor, G. (1979). "Polar Dielectrics and Their Applications." P.39. Univ. of California Press-Berkely.

83. Arlt, G. (1990). The Influence of Microstructure on the Properties of Ferroelectric Ceramics." Ferroelectrics 104, 217-226.

84. Vendik, O., and Mironenko, I. (1975). The Dimensional Effect in Thin ferroelectric Layers. Ferroelectrics 9 , 45-48.

85. Vendik, O., Ter-Martirosyan, L., Dedyk, A., Karmanenko, S., and Chakalov, R. (1993). High-Tc Superconductivity: New Applications of Ferroelectrics at Microwave Frequencies. Ferroelectrics 144, 33-43.

86. Vendik, O.G., and Zubko, S. (1997). Modeling the Dielectric Response of Incipient Ferroelectrics. J. Appl. Phys. 82, 4475-4483.

87. Gallagher, B. (October, 1997). Estimating and Measuring C/I in a GSM Wireless Local Loop Receiver. Microwave Journal, 70-83.

88. Hesler, J., Powell, N., Pfeifer, G., Egtvedt, M., Chovan, J., and Gawler, G. (1997). In "Electronic Engineers' Handbook" (D. Christiansen, Ed.), P. 18.58. $4^{\text {th }}$ ed. McGraw-Hill Press, New York.

89. Frerking, M., and East, J. (1992). Novel Heterojunction Varactors. Proc. IEEE 80, 1853-1860.

90. Galt, D., Rivkina, T., and Cromar, M. (1998). Microwave Tuning Quality and Power Handling of VoltageTunable Capacitors: Semiconductor Varactors Versus $\mathrm{Ba}_{1-\mathrm{x}} \mathrm{Sr}_{\mathrm{x}} \mathrm{TiO}_{3}$ Films. Mat. Res. Soc. Symp. Proc. 493, 341-346.

91. Kozyrev, A., Samoilova, T., Golovkov, A, Hollmann, E., Kalinkos, D. Loginov, V., Prudan, A., Mueller, C., Rivkin, T., and Koepf, G. (1997). Nonlinear Properties of $\mathrm{SrTiO}_{3}$ Films at Microwave Frequencies. Integrated Ferroelectrics 17, 263-271.

92. Kozyrev, A., Samoilova, T., Golovkov, A., Hollmann, E., Kalinikos, D., Loginov, V., Prudan, A., Soldatenkov, O., Galt, D., Mueller, C., Rivkin, T., and Koepf, G. (1998). Nonlinear Behavior of Thin Film $\mathrm{SrTiO}_{3}$ Capacitors at Microwave Frequencies. J. Appl. Phys. 84, 3326-3332.

93. Ramo, S., Whinnery, J., and Van Duzer, T. (1994). "Fields and Waves in Communication Electronics." P. 518. John Wiley and Sons, New York. 
94. Khanna, A., (1990) in "Dielectric Resonators" (D. Kajfez and P. Guillon, Ed.), p. 510. Vector Fields Press, Oxford, Mississippi.

95. Reynolds, A. (1974). Microwave Cavity Tuning Loop Including a Varactor. United States Patent No. $3,789,322$.

96. Mettoudi, I. (1990). Oscillator Having a Dielectric Resonator, and Electronic Frequency Tuning Using a Varactor, in Particular in the $22 \mathrm{GHz}$ Range. United States Patent No. 4,926,142.

97. Cohen, L., (1991). Millimeter Wave Oscillator With Flicker (1/F) Noise Suppression. United States Patent No. 5,019.791.

98. “Direct Data Distribution from Low Earth Orbit," J. M. Budinger, et al., NASA TM-107438 (1997).

99. Subramanyam, G. Van Keuls, F., and Miranda, F. (1998). A K-Band Tunable Microstrip Bandpass Filter using a Thin Film Conductor/Ferroelectric/Dielectric Multilayer Configuration. IEEE Microwave and Guided Wave Lett. 8. 78-80.

100. Subramanyam, G., Van Keuls, F., and Miranda, F. (1998). A Novel K-Band Tunable Microstrip Bandpass Filter using a Thin Film HTS/Ferroelectric/Dielectric Multilayer Configuration. IEEE MTT-S Digest, 1011-1014.

101. Van Keuls, F., Romanofsky, R., Bohman, D., and Miranda, F. (1998). Accepted for publication in Integrated Ferroelectrics.

102. Koul, S., and Bhat, B. (1991). "Microwave and Millimeter Wave Phase Shifters, Volume 1." Artech House, Boston.

103. Koul, S., and Bhat, B. (1991). "Microwave and Millimeter Wave Phase Shifters, Volume 2." Artech House, Boston.

104. Lynn, P. (1987). P. 65. "Radar Systems." Van Nostrand Press, New York.

105. Van Keuls, F., Romanofsky, R., and Miranda, F. (1998). Accepted for publication in Integrated Ferroelectrics.

106. Van Keuls, F. et al. (1998). A Ku-band Gold/Ba $\mathrm{Sr}_{1-x} \mathrm{TiO}_{3} / \mathrm{LaAlO}_{3}$ Conductor/Thin Film Ferroelectric Microstripline Phase Shifter for Room Temperature Communications Applications. Submitted to Microwave Optical Technology Letters.

107. Kozyrev, A., Osadchii, V., Soldatenkov, O., and Ivanov, A., Eletrotechnical Institute (St. Petersburg, Russia) (1997) Unpublished data. 


\section{LIST OF FIGURES}

Figure 1.-Pictorial overview of the Iridium System. Note that user-to-satellite link is at L-band. Reprinted by permission of John Wiley \& Sons, Inc." .

Figure 2.-Schematic diagram of conventional analog tuning technologies; (a) Mesa structure of $p+n$ semiconductor varactor $^{26}$ (Reprinted by permission of IEEE Press). (b) Magnetized ferrite toroid ${ }^{102}$ (Reprinted by permission of Artech House).

Figure 3.-Schematic diagrams. (a) Parallel plate paraelectric varactor configuration. (b) Planar varactor configuration.

Figure 4.-Capacitance and $\tan \delta$ of $0.4 \mathrm{~mm}$ BSTO (40/60) interdigital varactor with $16.5 \mathrm{~mm}$ gap, data taken at $298 \mathrm{~K}$. The resonant frequency of the two-port circuit was tuned from $2.54-3.00 \mathrm{GHz}$ by the dc bias, and the dc voltage was scanned over the entire range four times. $50 \mathrm{~V} \mathrm{dc}$ bias corresponds to an electric field of $3.03 \times 10^{4} \mathrm{~V} / \mathrm{cm}$. Data courtesy of SCT, Inc.

Figure 5.-Capacitance and $\tan \delta$ of $0.4 \mathrm{~mm}$ STO interdigital varactor with $17 \mathrm{~mm}$ gap, data taken at $70 \mathrm{~K}$. The resonant frequency of the two-port circuit was tuned from $2.31-3.08 \mathrm{GHz}$ by the dc bias, and the $\mathrm{dc}$ voltage was scanned over the entire range four times. $50 \mathrm{~V}$ dc bias corresponds to an electric field of $2.94 \times 10^{+} \mathrm{V} / \mathrm{cm}$. Data courtesy of SCT, Inc.

Figure 6.-Atomic Force Microscopy image of $0.4 \mathrm{~mm}$ BSTO film on $\mathrm{LaAlO}_{3}$ substate. The film was deposited using laser ablation at a substrate temperature of $750^{\circ} \mathrm{C}$, then post-annealed in an oxygen tube furnace at $1080^{\circ} \mathrm{C}$ for seven hours.

Figure 7.-Atomic Force Microscopy image of $0.4 \mathrm{~mm}$ STO (40/60) film on $\mathrm{LaAlO}_{3}$ substrate. The film was deposited using laser ablation at a substrate temperature of $750{ }^{\circ} \mathrm{C}$, then post-annealed in an oxygen tube furnace at $1080^{\circ} \mathrm{C}$ for seven hours.

Figure 8.- Intermodulation distortion caused by transmission of signals through nonlinear components.

Figure 9.- Test circuit for measuring third order intermodulation distortion in tunable dielectric varactors. (a) Planar capacitor. (b) Microstrip resonator.

Figure 10.-RF power levels of fundamental and third order intermodulation distortion as a function of input power. The lower abcissa $\left(U_{c m}\right.$ ) shows the RF voltage level across the varactor. Squares denote the RF input and output power levels with no bias applied to the varactor, and circles denote the performance with 100 volts applied to the
varactor.

Figure 11.-(a) Schematic of a tunable bandpass filter circuit. The dimensions are $\mathrm{W}=86.25 \mu \mathrm{m}, \mathrm{L}=6.8 \mathrm{~mm}$, $S_{1}=100 \mu \mathrm{m}, S_{2}=300 \mu \mathrm{m}, \mathrm{H}=1.33 \mathrm{~mm}$, and $w=12.5 \mu \mathrm{m}$, and $\mathrm{r}=200 \mu \mathrm{m}$. (b) Simulated data showing transmission $\left(S_{21}\right)$ versus frequency for different values of film $\varepsilon_{r}$. (c) Experimental data showing $S_{21}$ and reflection $\left(S_{11}\right)$ versus frequency as a function of $\mathrm{dc}$ bias.

Figure 12.-Microstripline side-coupled ring resonator. $W=406 \mu \mathrm{m}$ for the $25 \Omega$ ring and $89 \mu \mathrm{m}$ for the $50 \Omega$ ring. $\mathrm{w}=89 \mu \mathrm{m}, \mathrm{g}=25 \mu \mathrm{m}$, and $\mathrm{r}=1694 \mu \mathrm{m}$.

Figure 13.-Effect of dc bias on the $3 \lambda$ resonant frequency $\left(f_{0}\right)$ and sharpness of resonance $d_{n}{ }_{n}^{-1}$ for a Au/STO/LAO ring resonator at $77 \mathrm{~K}$. The ring is biased at $V_{R}$ and line at $V_{L}$, where $V_{R}>V_{L}$.

Figure 14. - Performance of tunable bandreject filter used in $8.5-10.5 \mathrm{GHz}$ suite. Each filter contains three tunable resonators, and the resonators are overlapped to increase the signal rejection. 
Figure 15.-(a) Single-element phase shifter (with input/output 50 to $25 \mathrm{~V}$ transformers) $\mathrm{S}=12.7 \mathrm{~mm}$,

$\mathrm{W}=76.2 \mathrm{~mm}$. (b) Schematic of eight-element, $50 \mathrm{~V}$ coplanar microstrip phase shifter. $\mathrm{S}=7.5 \mathrm{~mm}$ and $\mathrm{W}=25 \mathrm{~mm}$.

Figure 16.-Transmission magnitude and phase values for a $50 \Omega$, eight-element coplanar microstrip phase shifter using YBCO $(0.35 \mu \mathrm{m} / \mathrm{STO}(1.0 \mu \mathrm{m}) / \mathrm{LAO}(254 \mu \mathrm{m})$. Data were taken at $\mathrm{T}=40 \mathrm{~K}$ and $16 \mathrm{GHz}$. (b) Same phase shifter as in (a), but data taken at $\mathrm{T}=77 \mathrm{~K}$ and $16 \mathrm{GHz}$.

Figure 17.-(a) Phase shift of $\mathrm{S}_{21}$ versus dc bias voltage for a $25 \Omega$ single element $\mathrm{Au}(2.5 \mu \mathrm{m}) / \mathrm{Ba}_{0.6} \mathrm{Sr}_{0.4} \mathrm{TiO}_{3}$ $(300 \mathrm{~nm}) / \mathrm{LAO}(254 \mu \mathrm{m})$ phase shifter. Data were taken at $300 \mathrm{~K}$. (b) Phase shift of $S_{21}$ for a $50 \Omega$ eight-element Au $(2.5 \mu \mathrm{m}) / \mathrm{Ba}_{0.5} \mathrm{Sr}_{0.5} \mathrm{TiO}_{3}(300 \mathrm{~nm}) / \mathrm{LAO}(254 \mu \mathrm{m})$ phase shifter at $302 \mathrm{~K}$. (c) Magnitude of $\mathrm{S}_{21}$ for phase shifter in (b) at $302 \mathrm{~K}$.

Figure 18.-Schematic of transmission-mode, $1.9 \mathrm{GHz}$ phase shifter. Tuning is accomplished by varying the capacitance of tunable dielectric varactors located in the shunt arms. 